\title{
Cardiovascular Magnetic Resonance Imaging and Heart Failure
}

\author{
Chuanfen Liu $^{1,2} \cdot$ Victor A. Ferrari $^{1} \cdot$ Yuchi Han $^{1}$ (B) \\ Accepted: 18 January 2021 / Published online: 8 March 2021 \\ (C) The Author(s), under exclusive licence to Springer Science+Business Media, LLC part of Springer Nature 2021
}

\begin{abstract}
Purpose of Review The purpose of this review is to summarize the application of cardiac magnetic resonance (CMR) in the diagnostic and prognostic evaluation of patients with heart failure (HF).

Recent Findings CMR is an important non-invasive imaging modality in the assessment of ventricular volumes and function and in the analysis of myocardial tissue characteristics. The information derived from CMR provides a comprehensive evaluation of HF. Its unique ability of tissue characterization not only helps to reveal the underlying etiologies of HF but also offers incremental prognostic information.
\end{abstract}

Summary CMR is a useful non-invasive tool for the diagnosis and assessment of prognosis in patients suffering from heart failure.

Keywords Cardiovascular magnetic resonance $\cdot$ Heart failure $\cdot$ Late gadolinium enhancement $\cdot$ Cardiomyopathy

\section{Introduction}

Heart failure (HF) is a complex clinical syndrome caused by structural and/or functional cardiac abnormalities [1, 2]. As the population age, the prevalence and cost of $\mathrm{HF}$ will continue to increase over time. It is estimated that from 2012 to 2030, the prevalence of HF will increase by $46 \%$, and the cost of HF will increase to $\$ 69.8$ billion by 2030 in the USA [3]. Abnormalities of the myocardium, valves, pericardium, endocardium, and heart rhythm can all cause HF. Correctly identifying the underlying etiology of HF is crucial as the subsequent treatment may differ and the outcomes may be impacted in these patients $[1,2,4]$.

Cardiac magnetic resonance (CMR) has become a useful non-invasive tool for the diagnosis and assessment of

This article is part of the Topical Collection on Heart Failure

Yuchi Han

yuchi.han@pennmedicine.upenn.edu

Chuanfen Liu

liucf-99@163.com

Victor A. Ferrari

vferrari@pennmedicine.upenn.edu

1 Cardiovascular Division, Department of Medicine, Perelman School of Medicine of the University of Pennsylvania, Philadelphia, PA, USA

2 Department of Cardiology, Peking University People's Hospital, Beijing, China prognosis in patients suffering from heart failure. CMR is superior in the assessment of left ventricular (LV) volumes and function and in the analysis of wall motion abnormalities and myocardial tissue characteristics compared with echocardiography. Myocardial fibrosis is a common pathologic manifestation in heart failure, and the pattern of fibrosis differs between different etiologies [5]. Late gadolinium enhancement (LGE) CMR enables non-invasive quantification of myocardial fibrosis and is one of the most widely used CMR techniques in identifying etiology and assessing prognosis in patients with HF. However, LGE can only delineate focal but not diffuse interstitial fibrosis. Besides fibrosis, other common pathophysiologic features of HF include intracellular abnormalities, myocardial edema, and deposition of extracellular proteins. Myocardial tissue characterization parameters (T1, T2, T2*, and extracellular volume (ECV)) can quantify tissue alterations in patients with HF, including intracellular changes of cardiomyocyte (fat deposition or iron overload), extracellular changes in the myocardial interstitium (e.g., fibrosis or deposition of amyloid proteins), or both (myocardial infarction and/or edema) [6-10]. Native T1 reflects the changes in myocardium involving the myocytes and the interstitium, and $\mathrm{ECV}$, calculated by $\mathrm{T} 1$ pre and post administration of gadolinium and hematocrit, reflects the myocardial interstitial expansion by fibrosis, fluid, or other protein deposits [10]. Native T1 as a non-exogenous contrast-based endogenous tissue characterization parameter is especially useful in patients who cannot receive gadolinium contrast due to severe renal dysfunction. T2 mapping is sensitive to myocardial 
edema. T2* is a useful tool to assess tissue iron deposition [8]. CMR imaging in HF has been endorsed as appropriate in multiple heart failure guidelines and has been shown to change overall patient management in up to $65 \%$ of patients with heart failure [1, 2, 7, 11]. European Association for Cardiovascular Imaging recommended that in the diagnostic evaluation of patients with $\mathrm{HF}$, parametric mapping should be considered [6]. In this context, we aim to discuss each specific cardiomyopathy as it relates to CMR imaging in heart failure.

\section{Ischemic Cardiomyopathy}

Coronary artery disease (CAD) is the most common and a potentially treatable cause of HF and needs to be assessed in every patient with a new diagnosis of HF. Regional wall motion abnormalities are readily identified on steady-state free procession (SSFP) cine imaging (Fig. 1a, b). LGE on contrast CMR was validated to distinguish between irreversible (hyper-enhanced) and reversible (not hyper-enhanced) ischemic injury independent of wall motion and infarct age in an canine myocardial infarction model [12]. LGE in ischemic cardiomyopathy (ICM) usually occurs in the subendocardial to transmural involvement corresponding to a coronary artery distribution [5, 13, 14] (Fig. 1c, d). An international multicenter trial including 566 patients with MI showed that the sensitivity of CMR for detecting MI was $99 \%$ and $94 \%$ in acute and chronic infarction, respectively, and the accuracy for identifying MI location was $99 \%$ and $91 \%$ in acute and chronic infarction, respectively [15]. In a study prospectively enrolled 71 patients with HF without a previous history of MI, CMR could identify the presence of obstructive CAD using coronary angiography as a diagnostic standard with sensitivity of $81 \%$, specificity of $91 \%$, and diagnostic accuracy of $87 \%$ [16]. This was confirmed by another study of 60 patients with HF, in which LGE-CMR had a sensitivity of $98 \%$, specificity of $84 \%$, and diagnostic accuracy of $93 \%$ in detecting CAD [17].

In addition to LGE, where the pattern of fibrosis can detect scar due to MI, there is cumulating evidence that stress perfusion CMR performs well to identify myocardial ischemia (Fig. 1e, f). The Magnetic Resonance Imaging for Myocardial Perfusion Assessment in Coronary Artery Disease Trial (MR-IMPACT) I, MR-IMPACT II, and Clinical Evaluation of Magnetic Resonance Imaging in Coronary Heart Disease (CE-MARC) study demonstrated equal or superior performance of stress perfusion CMR for the detection of CAD compared to single-photon emission computed tomography (SPECT) [18-20]. The recently published SPINS (The Clinical Impact of Stress CMR Perfusion Imaging in the United States) study further demonstrated that patients without ischemia by stress perfusion CMR or LGE experienced a

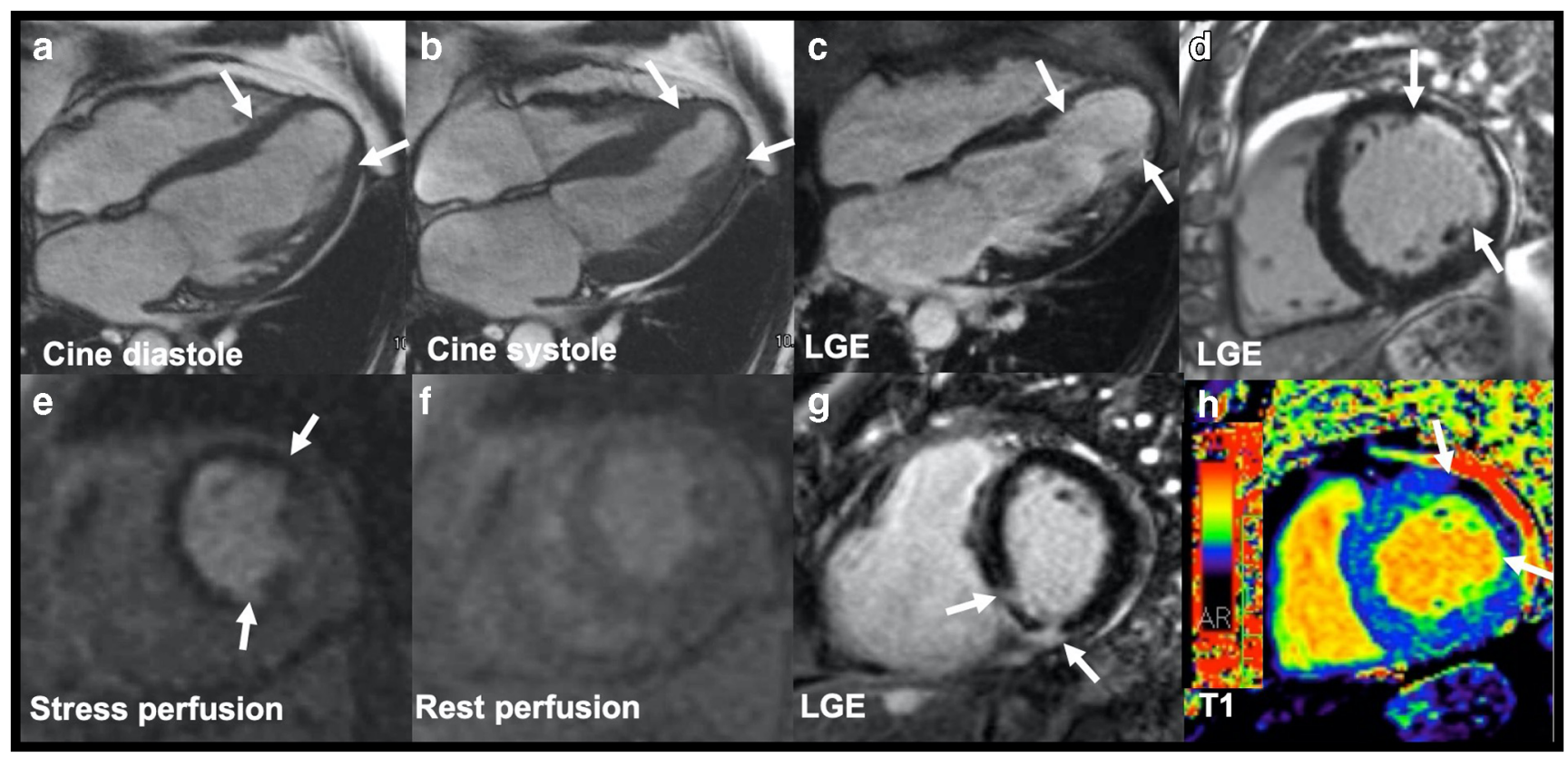

Fig. 1 Ischemic cardiomyopathy images in cine, late gadolinium enhancement (LGE), stress perfusion, microvascular obstruction, and hemorrhage. a, b Still frames from 4-chamber cine in end-diastole and end-systole showing hypokinesis of the mid-ventricle to the apex with an apical aneurysm (between arrows) in a 65-year-old woman. c, d LGE images showing subendocardial delayed enhancement in the apical walls (between arrows) of the 65-year-old woman and subendocardial LGE in a 78-year-old man with an old myocardial infarction (MI). e, f Stress perfusion image showing perfusion defects of the anterior wall and the septum compared to the rest perfusion image, suggesting reversible ischemia (between arrows) in the 65-year-old woman. g LGE image showing microvascular obstruction in the basal inferoseptum (between arrows) in a 40-year-old man with acute MI. h T1 mapping showing the dark core of intramyocardial hemorrhage (between arrows) in the 78year-old man with the corresponding LGE slice in image (d) 
low incidence of cardiac events, a low need for coronary revascularization, and low cost spent on subsequent ischemia testing with a 4-year follow-up [21].

The presence and extent of LGE predicts prognosis in patients with heart failure regardless of etiology [22-26]. For patients with CAD, the presence and extent of LGE is an independent predictor of mortality [27-29]. A study of 349 patients with ICM and reduced left ventricular ejection fraction (LVEF) showed the extent of myocardial scar detected by LGE was associated with mortality in these patients [29]. T1 mapping has also been used to evaluate the prognosis of CAD. A study with 665 patients with CAD undergoing CMR imaging with $\mathrm{T} 1$ mapping and LGE demonstrated that native T1 and LGE were predictors of survival and major adverse events, while native $\mathrm{T} 1$ of noninfarcted myocardium is the sole independent predictor of allcause mortality [30].

Parametric mapping techniques may be helpful to determine the presence of microvascular obstruction (MVO) and intramyocardial hemorrhage in patients with CAD [31, 32] (Fig. 1g, h). MVO is caused by noreflow in patients with ST-segment elevation myocardial infarction (STEMI), and it appears as a dark area within hyper-enhanced infarcted myocardium [33]. A number of studies have demonstrated that MVO was associated with adverse LV remodeling and outcome [32, 34, 35]. In a study of 203 patients with STEMI, who underwent CMR including T2*, myocardial hemorrhage (persistent iron) was found to be associated with worse LV function and long-term prognosis [31]. Both $\mathrm{T} 1$ and $\mathrm{T} 2$ mapping performed equally well when a hypointense core was identified on these images to detect intramyocardial hemorrhage as compared to $\mathrm{T} 2 *$ [36].

CMR may influence therapeutic decisions as LGE can identify reversible and irreversible myocardial injury before revascularization [37-42]. Early studies showed that LGE could delineate myocardial viability by quantifying transmurality of scar, with transmural LGE significantly related to the less likelihood of improvement in regional function after revascularization [37, 42]. Another study including 60 patients with STEMI found that T1 mapping was able to differentiate reversible and irreversible myocardial damage, and was a strong predictor of LV remodeling [38]. In patients undergoing complete revascularization, favorable survival is reported as compared to patients who receive incomplete revascularization, which was not superior to medical management [43]. This suggests that the evaluation of myocardial viability with CMR combined with the feasibility of complete revascularization is important in order to identify patients who may benefit from revascularization, although the assessment of viability in ICM remains controversial and needs further study [40].

\section{Non-ischemic Cardiomyopathy}

\section{Dilated Cardiomyopathy}

Dilated cardiomyopathy (DCM) is a common etiology of heart failure. It is characterized by ventricular chamber dilation and decreased systolic function in the absence of other identifiable etiologies such as ischemic heart disease or valvular heart disease. Interactions between genetic and environmental factors can influence the phenotype of DCM [44], which depend not only on the genotype but also on epigenetics, inflammation, toxic factors, diabetes, and other acquired diseases [45]. LGE was detected in approximately $30-40 \%$ of patients with DCM [46-49], with the common pattern being mid-wall septal LGE $[46,48]$ (Fig. 2a-c). CMR is useful to assess patients with early stage DCM. In a study of 150 phospholamban (PLN) p.Arg14del mutation carriers, LGE was detected in nearly $30 \%$ of carriers with preserved LVEF, suggesting fibrosis may be an early feature of PLN p.Arg14del cardiomyopathy which can cause HF and ventricular arrhythmia [50]. Native T1 and ECV reflecting the degree of diffuse myocardial fibrosis have been confirmed by human and animal studies [51-53]. A study found ECV values obtained from CMR were significantly different between early DCM (LVEF 45-55\%), DCM (LVEF < 45\%), and healthy volunteers ( $25 \pm 4$ vs. $27 \pm 4$ vs. $23 \pm 3 \%$, all $p<$ 0.05 ), and a strong correlation was detected between ECV and collagen volume fraction (CVF) assessed by histological analysis from endomyocardial biopsies [53].

CMR can also help to assess prognosis in patients with non-ischemic cardiomyopathy [53-58]. A study including 472 patients with DCM found that mid-wall fibrosis was an independent predictor for all-cause mortality after adjustment for LVEF and other clinical factors such as heart rate and blood pressure [49]. Another study also demonstrated the presence of mid-wall LGE in patients at first diagnosis of DCM was independently associated with subsequent adverse cardiac events and HF rehospitalization [56]. On the other hand, a study enrolling 120 patients with new-onset HF showed an absence of myocardial fibrosis which indicated a favorable prognosis [22]. A meta-analysis including 34 studies and 4554 patients with DCM showed that LGE on CMR was present in $44.8 \%$ of patients, and LGE was associated with worse prognosis, while the absence of LGE was associated with LV reverse remodeling [57]. T1 mapping is also used to prognosticate in patients with DCM $[53,58]$. In a multicenter observational study enrolling 637 patients with DCM, T1 mapping predicted all-cause mortality and HF events and performed better than LGE [58], which might be due to the diffuse nature of fibrosis in DCM. Myocardial strain assessed by CMR has been used to measure global and regional myocardial deformation and contractility [59]. In a study of 210 patients with DCM, LV longitudinal strain was 


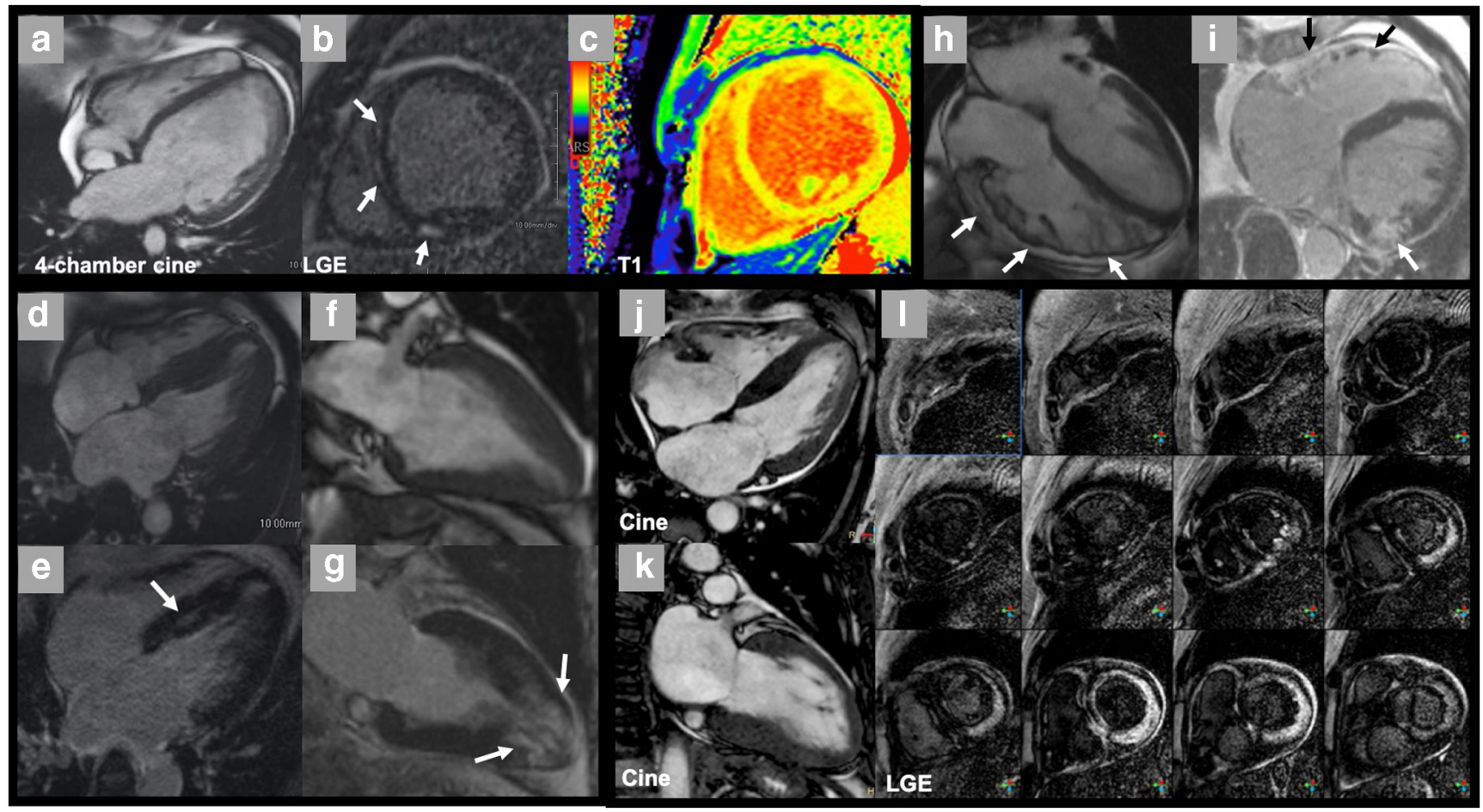

Fig. 2 Non-ischemic cardiomyopathy. Dilated cardiomyopathy images in cine, late gadolinium enhancement (LGE), and T1 mapping. a CMR end-diastolic frames from 4-chamber cine showing biventricular dilation in a 23-year-old man with chronic heart failure. b LGE imaging showing mid-myocardial delayed enhancement in the septum and the inferior wall (arrows). c T1 mapping shows diffusely elevated signals consistent with diffuse fibrosis. Hypertrophic cardiomyopathy (HCM) presentations in cine and late gadolinium enhancement. $\mathbf{d}, \mathbf{f}$ 4-chamber or 2-chamber long-axis cine images showing different phenotypes of HCM. e, g LGE images showing patchy delayed enhancement (arrows) in corresponding patient cine views. d, f Asymmetric septal hypertrophy. e, g Apical HCM. Arrhythmogenic right ventricular cardiomyopathy. $\mathbf{h}$ Still frame from 4chamber cine in end-diastole showing dilated, trabeculated right ventricle with regional thinning and microaneurysm (white arrows) in a 76-yearold man. i Late gadolinium enhancement image showing enhancement in the right ventricular wall (black arrows). The left ventricular LGE was due to a left circumflex occlusion in this patient, not left ventricular involvement in ARVC (white arrow). Amyloidosis. j, k Still frames from 2-chamber and 4-chamber cines showing bi-atrial enlargement, increased wall thickness of left ventricle, and trace pericardial effusion in a 65-year-old man. 1 Serial short-axis late gadolinium enhancement images showing diffuse transmural enhancement in the basal to mid-left ventricular myocardium, gradually decreasing to a global subendocardial pattern in the mid-ventricle. Note that the blood pool is dark which is related to abnormal blood pool gadolinium dynamics in the presence of diffuse amyloid deposition in the body an independent prognostic parameter of survival outperforming clinical parameters and standard CMR parameters, such as LVEF and LGE [60].

Despite significant advances in medical therapies for heart failure, the response of different patients to drug treatment varies dramatically. Different studies have demonstrated that myocardial fibrosis detected by CMR is associated with response to drug therapy in patients with HF [61-63]. One of the mechanisms that medicine improves the prognosis of patients with HF is reversing ventricular remodeling. In a study including 31 patients with non-ischemic cardiomyopathy (NICM) treated with carvedilol, LV function improved more in patients without LGE at baseline than in patients with LGE [63].

Implantable cardiac defibrillator (ICD) is an effective strategy to prevent sudden cardiac death (SCD) in patients with DCM. LVEF $\leq 35 \%$ is recommended threshold for ICD implantation [1]; however, many patients suffer from SCD with LVEF $>35 \%$ [64]. In a community-wide study of SCD, only one-third of the SCD cases that underwent evaluation before cardiac arrest had severe LV dysfunction as defined by LVEF $\leq 35 \%$ [64]. As fibrosis/scar is considered as ventricular arrhythmias substrate $[65,66]$, CMR is able to identify patients at high risk of SCD [25, 47, 67-69]. A study enrolled 137 patients referred for evaluation of ICD placement and found that the patients with LVEF $>30 \%$ and scar $>5 \%$ LV mass had similar risk compared to patients with LVEF $\leq 30 \%$, while those with LVEF $\leq 30 \%$ but no scar had similar low risk compared to patients with LVEF $>30 \%$ [69]. These studies suggest more research in myocardial tissue characteristics is needed to improve risk stratification of SCD in DCM beyond LVEF.

Cardiac resynchronization therapy (CRT) is considered an important treatment option for patients with end-stage HF. However, about $30 \%$ of patients do not respond to CRT [70, 71]. Studies have evaluated the relationship between myocardial scar and response to CRT [72-74]. In a study of 40 endstage heart failure patients treated with CRT, patients with 
posterolateral scar tissue had significant lower response rate compared to patients without posterolateral scar tissue [73].

\section{Hypertrophic Cardiomyopathy}

Hypertrophic cardiomyopathy (HCM) is the most common hereditary cardiomyopathy with a highly variable phenotypic expression. The most common hypertrophied segments in HCM are basal anteroseptum and the contiguous anterior free wall [75]; however, any segment can be hypertrophied and CMR has advantages in defining LV segmental wall thickness irrespective of echocardiographic window [76, 77]. Myocardial fibrosis is detected by CMR-LGE in around $70 \%$ of patients with HCM, and the LGE is typically nonsubendocardial predominantly in areas of hypertrophy [78] (Fig. 2d-g).

CMR is also useful to identify the early phase of HCM as shown in a study of 40 sarcomere mutation carriers with normal echo wall thickness ( $<12 \mathrm{~mm})$, and CMR identified mild hypertrophy (12.6-14 $\mathrm{mm})$ in 4 subjects [79].

The results of studies using CMR to characterize HCM genotype-phenotype relationships are inconsistent. In a large HCM family, the same point mutation manifests different phenotypes assessed by CMR, and elevated T1 and ECV values were also present in phenotypically negative mutation carriers [80]. A multicenter study found no significant differences in CMR phenotypic characteristics between patients with $\beta$ myosin heavy chain (MYH7) gene mutations $(n=53)$ versus myosin-binding protein C (MYBPC3) gene mutations $(n=75)$, including structure characteristics, such as LV mass and maximal wall thickness, and the prevalence and extent of LGE [81]. Another study showed MYBPC3 mutations were more likely to impair ventricular function compared with MYH7 mutations [82]. More studies are still needed to understand the relationship between genotypes and phenotypes.

CMR can differentiate HCM from other causes of left ventricular hypertrophy (LVH), including athlete's heart, hypertensive cardiomyopathy, metabolic cardiomyopathy such as Fabry disease, and infiltrative cardiomyopathy such as amyloid [83].

Intensive exercise is associated with ventricular hypertrophy. The pattern and location of myocardial fibrosis determined by biopsy or CMR vary widely in athletes, and the most common findings are nonspecific LGE, located in the right ventricular insertion points or the septum [84]. The diagnosis of HCM is supported if hypertrophy remains assessed by CMR after prescribed deconditioning while the diagnosis of athlete's heart is supported if the wall thickness regresses by more than $2 \mathrm{~mm}$ [85]. In a study of 50 patients with HCM, 40 athletes, and 35 sedentary volunteers, the T1 values and ECV of the thickest segment in athletes were lower than HCM [86]. Most of the studies showed there were no significant differences in terms of T1 mapping and ECV between athletes and controls [87, 88].
In clinical practice, differentiation of hypertensive LVH from HCM can be challenging. Nonspecific LGE can be identified in up to $50 \%$ of the patients with hypertension [78]. Hypertension can lead to diffuse myocardial fibrosis which may not be detected by LGE [89], but ECV can be elevated in hypertensive patients with LVH and not in the absence of LVH $[90,91]$. In a study of 95 patients with HCM, 23 HCM gene carriers, and 69 with hypertension, both native T1 and ECV were significantly elevated in HCM compared with hypertensive patients, including in subgroup comparisons of HCM without LGE and hypertensive patients with LV wall thickness of $>15 \mathrm{~mm}$ [92].

Typical features of cardiac amyloid will be discussed in the following specific section dedicated to amyloid. In Fabry disease, native T1 values are often normal or decreased in patients with hypertrophy due to the increased fat content in the myocardium. This characteristic is very helpful in distinguishing Fabry disease from other hypertrophic diseases where increased T1 is often present due to fibrosis or extracellular protein deposition.

HCM is the most frequent cause of SCD in young people [93]. CMR allows for precise phenotypical depiction of the severity and distribution of hypertrophy and tissue characterization and is becoming an effective tool for further risk stratification of patients with HCM [76, 83, 94]. The presence and extent of LGE on CMR is associated with ventricular tachyarrhythmias and SCD $[67,95,96]$. A recent study demonstrated native T1 and ECV elevation in patients with HCM in the absence of LGE, and follow-up data showed elevated T1 and ECV were associated with SCD [97].

Heat failure is another complication of HCM. The majority of patients with hypertrophic obstructive cardiomyopathy (HOCM) present as HF with preserved ejection fraction (HFpEF), while only a minority of patients with HCM develop reduced ejection fraction (HFrEF) at a later stage [98]. Fibrosis progression detected by LGE-CMR was associated with LV thinning, increased LV end-diastolic volume, reduced LVEF, and adverse clinical outcomes [99]. Progression of LGE was higher in patients with worsening cardiac function [100].

\section{Arrhythmogenic Right Ventricular Cardiomyopathy}

Arrhythmogenic right ventricular cardiomyopathy (ARVC) is an inherited disease characterized by fibro-fatty replacement of predominantly the right ventricular (RV) myocardium, leading to ventricular arrhythmias and RV dysfunction [101-103]. The diagnosis of ARVC is based on the presence of major and minor criteria including structural, histological, electrocardiographical, arrhythmic, and genetic factors [104]. Echocardiography has limitations in assessing the right ventricle [104, 105], and CMR has become an important imaging modality in the diagnosis and risk stratification of ARVC by 
detecting RV dilation, abnormal global and regional wall motion, and tissue characterization [102, 104] (Fig. 2h, i). Genotype-phenotype correlation studies showed the wide spectrum of ARVC, including RV only, biventricular, and left dominant manifestations [106], thus the disease is being referred to with a more comprehensive term as "arrhythmogenic cardiomyopathy" [106, 107]. LGE can be found in approximately $60-80 \%$ of patients with ARVC; however, the finding of biventricular LGE has a differential diagnosis including myocarditis and sarcoidosis which need to be carefully considered [108-110]. CMR myocardial feature tracking can quantitatively measure regional abnormalities. In a study analyzing 21 patients with ARVC undergoing electroanatomic mapping and CMR, strain was lower in segments with dense scar on electroanatomic mapping compared with the rest of right ventricle, and regional abnormal wall strain predicted arrhythmogenic substrate better than LGE [111].

Risk stratification is critical as ARVC is a common cause of sudden death in young people and athletes [112]. A study evaluated the prognostic role of CMR in patients with definite $(n=52)$, borderline $(n=50)$, and possible $(n=73)$ diagnosis of ARVC, and the results showed that LV involvement (fat infiltration and/or LGE) was an independent predictor of cardiac events [113]. A recent study demonstrated that LV global strains evaluated by CMR feature tracking could detect early LV dysfunction and predict adverse cardiac events in patients with ARVC [114].

\section{Cardiac Amyloidosis}

Cardiac amyloidosis (CA) is caused by the deposition of misfolded proteins in the extracellular space [115]. The two most common types are light-chain (AL) amyloidosis and transthyretin (ATTR) amyloidosis. CA should be considered in patients with HFpEF [116], and early recognition is of utmost importance as early treatment may positively impact prognosis.

One of the typical characteristics of CA is ventricular hypertrophy, and the most common LGE pattern is global transmural or subendocardial enhancement, with high native T1 and ECV [117-120]. Other common morphological features of CA in addition to LV hypertrophy include atrial dilation, thickening of the atrial septum, and pericardial effusion.

Due to its excellent ability to identify tissue characteristics, CMR has become an important tool in the diagnosis and assessment of amyloidosis [117-119, 121, 122]. Global transmural or subendocardial LGE is the most common pattern in patients with CA $[117,119]$ (Fig. 2j-1). LGE improves cardiac amyloidosis detection, but LGE may not detect CA patients in the early phase [117]. T1 mapping and ECV have nicely demonstrated the diagnosis potential in patients with suspected CA $[118,120,123,124]$. A recent study demonstrated that native $\mathrm{T} 1$ enabled us to diagnose CA without the need for gadolinium in suspected amyloidosis [118•]. Williams et al. [125] found the relative apical sparing of longitudinal strain may be helpful to differentiate CA from other cardiomyopathies with LV hypertrophy, similar to echo cardiographic findings. CMR is also used to investigate the different myocardial characteristics between AL and ATTR amyloidosis. A study including 46 patients with AL amyloidosis and 51 patients with ATTR amyloidosis showed that transmural LGE was more common in ATTR amyloidosis (90\%) compared with patients with AL amyloidosis $(37 \%)$ [126]. Another study found that myocardial native T2 was significantly higher in AL amyloidosis than in ATTR amyloidosis, which suggested that $\mathrm{T} 2$ may be an additional marker to distinguish AL and ATTR amyloidosis [127].

CMR techniques such as LGE, T1 mapping, and ECV are also helpful in the assessment of prognosis in CA $[117,120$, 123, 124]. Transmural LGE was significantly associated with adverse prognosis with a 2 -year survival of $61 \%$ in patients with transmural LGE, compared with $81 \%$ of subendocardial LGE, and 92\% of no LGE [117]. A study including 100 patients showed that native T1 and ECV could predict mortality in patients with light-chain amyloidosis [124]. Another study demonstrated that both native T1 and ECV correlated with mortality in ATTR amyloidosis, but ECV had a better prognostic value than native T1 [120].

Additional studies evaluated the association of RV involvement and feature tracking strain with prognosis of CA. RV enddiastolic volume index and RV-LGE were independently associated with mortality in AL-related CA [128]. CMR-derived strain parameters were independent prognostic factors in allcause mortality in patients with AL amyloidosis [128, 129].

CMR has shown the potential to monitor treatment progress in CA. A study including 31 patients with AL amyloidosis found that the prevalence of reduction in ECV was higher in patients with good hematologic response than in patients with partial/no response [130].

\section{Inflammatory Cardiomyopathies}

\section{Myocarditis}

Myocarditis is an inflammatory disease of the myocardium caused by infectious or non-infectious etiologies, and the most common etiology is a viral infection [131] (Fig. 3a-h). Acute orthotopic heart transplant rejection and cancer immunotherapy are examples of non-infectious causes of myocardial inflammation (Fig. 3i-n). Acute myocarditis can present as new-onset HF, and some DCM may evolve from chronic sequelae of myocarditis. CMR has become a preferred imaging tool for the diagnosis and evaluation of patients with myocarditis as it not only assesses the ventricular morphology and function but also evaluates the tissue characteristics such as edema and/or fibrosis. 


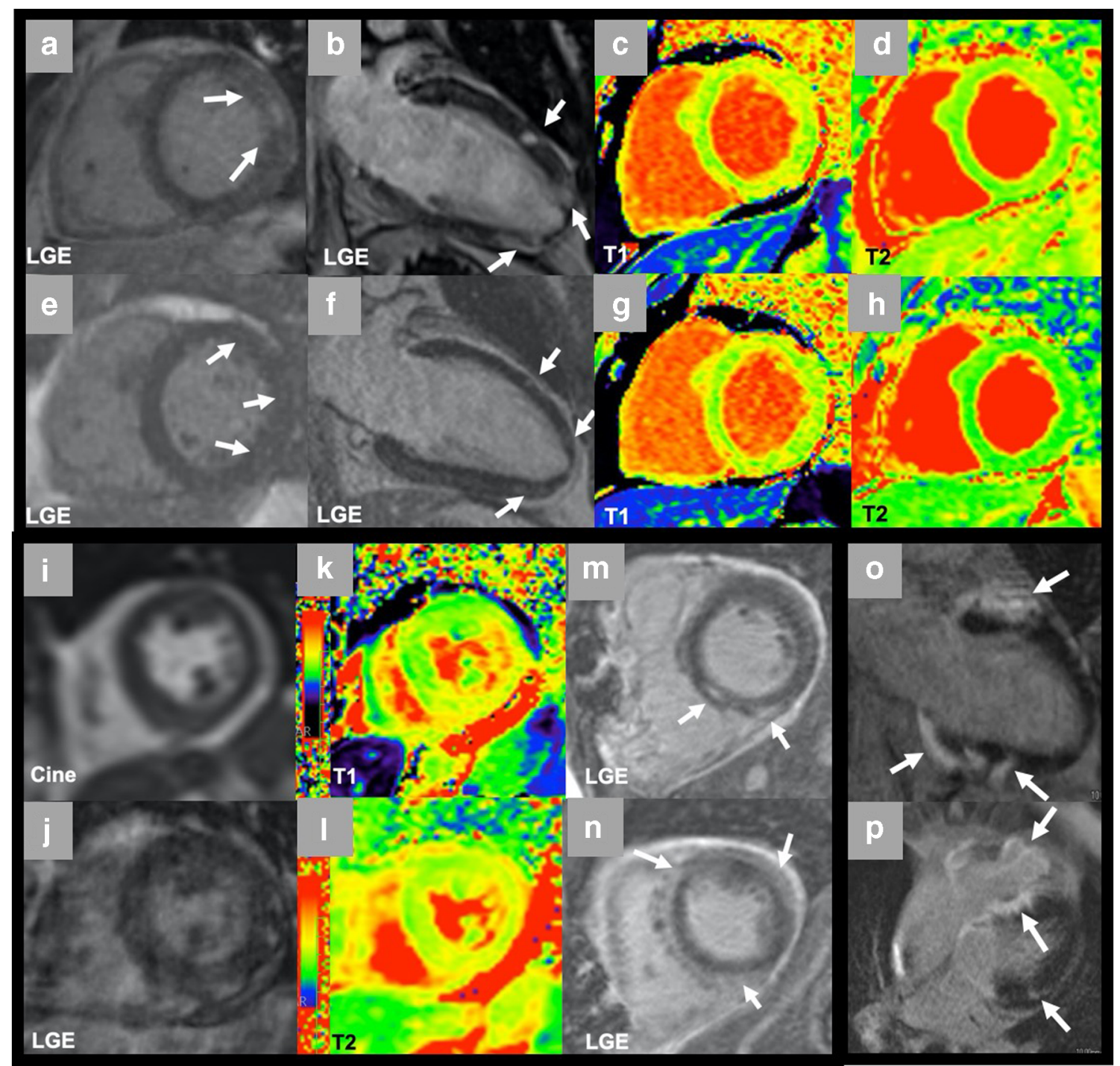

Fig. 3 Inflammatory cardiomyopathy. Acute myocarditis with late gadolinium enhancement (LGE) imaging, T1 and T2 mapping (top row), and follow-up in 3 months (second row) in a 27-year-old male. LGE images showing mid-myocardial to subepicardial LGE in the basal anterolateral wall on the short axis (a) and 2-chamber view (b) and in the apex on the 2-chamber view (B) (arrows). T1 mapping (c) and T2 mapping (d) at the base both showing elevated signal (yellow areas as compared to green areas which is normal). Three months later, there was diminished LGE signal in the corresponding short axis (e) and 2-chamber slices (f). At follow-up, T1 signal remained elevated (g), but T2 signal had returned to normal (h). Cancer immunotherapyinduced myocarditis and acute transplant rejection. Cine imaging of a 62-

The Lake Louise criteria to diagnose myocarditis was formulated in 2009, defining myocarditis as 2 out of 3 CMR criteria being positive: edema (increased $\mathrm{T} 2$-weighted signal), hyperemia (early gadolinium enhancement), and necrosis (LGE) [132]. LGE pattern is commonly subepicardial and/or mid-wall but can also involve the endocardium, albeit not in a coronary artery distribution [13]. However, diagnostic accuracy of the Lake Louise criteria in patients with suspected chronic myocarditis is not as good as suspected acute year-old female with immunotherapy-induced myocarditis (i) and LGE showing no convincing enhancement (j), but T1 mapping (k) and T2 mapping (I) both demonstrated signal elevation. LGE images $(\mathbf{m}, \mathbf{n})$ of a 34-year-old female with acute cellular rejection of the transplanted heart showing multifocal mid-myocardial delayed enhancement in the basal septum and basal inferior wall ( $\mathbf{m}$, arrows), and the entire subepicardium to mid-myocardium in the mid to apical myocardium (n, arrows). Sarcoidosis. LGE images of a 50-year-old man showing multifocal left ventricular subepicardial, mid-myocardial, and subendocardial delayed enhancement, and LGE of the right ventricle (o, p, arrows)

myocarditis [133]. Studied have shown T1 mapping offered better diagnosis performance than Lake Louise criteria in the diagnosis of acute myocarditis [134]; however, T1 mapping is not specific to discriminate between acute and chronic myocarditis [135]. The MyoRacer-Trial demonstrated that only T2 mapping had acceptable diagnostic accuracy in patients with chronic symptoms (defining symptom duration $>14$ days) [135]. Another study with longitudinal follow-up of 18 patients with acute myocarditis showed that $\mathrm{T} 2$ normalized after 
6 months although native T1 remained elevated; thus, T2 mapping can differentiate between acute and healed myocarditis [136]. The application of T1 and T2 mapping techniques allow for the updated Lake Louise criteria which includes at least one T2-based marker for myocardial edema, and at least one T1-based marker for myocardial injury [137••] (Fig. 3ah). Although EMB is the current gold standard for the diagnosis of definite myocarditis, CMR is recommended for the evaluation of myocarditis by different scientific statements and guidelines due to its ability to provide a non-invasive approach to detect and exclude myocardial inflammation [2, 138, 139].

The pandemic of coronavirus disease 2019 (COVID-19) continues to cause morbidity and mortality worldwide. The cardiac complications of this disease were associated with worse outcomes [140]. In a study of 26 recovered patients with nonspecific cardiac symptoms but without cardiovascular comorbidities (except two with hypertension), CMR detected cardiac involvement in 58\% of patients based on T1, T2, ECV, and LGE abnormalities 1-2 months after symptom onset [141]. Puntmann et al. [142] further evaluated the presence of myocardial findings in 100 unselected patients recovered from COVID-19, and CMR revealed cardiac involvement in $78 \%$ of patients and ongoing myocardial inflammation in $60 \%$ of patients $2-3$ months after the infection, occurring at a much higher percentage as compared to a comorbidity-matched cohort. In another study, 22 collegiate athletes with prior asymptomatic or mild course of ambulatory COVID-19 underwent CMR [143], LGE was found in 9\% of athletes, and one athlete met criteria for myocarditis, while no athletes had abnormal troponin I, electrocardiograms, or LVEF $<50 \%$ on echocardiography [143]. These studies indicate the need for CMR investigation of the long-term cardiovascular involvement of COVID-19.

CMR also has prognostic value in patients with myocarditis [144, 145]. In a study of 222 patients with myocarditis diagnosed by endomyocardial biopsy, LGE was a strong predictor of all-cause mortality [144]. The finding was confirmed by another study of 670 patients with suspected myocarditis in which the presence of LGE was significantly associated with major adverse cardiac events (MACEs) [145]. On the other hand, a study enrolling 405 patients with clinically suspected myocarditis showed patients with normal CMR had a favorable prognosis [146]. Given high false-negative rate of biopsy, CMR provides potential diagnostic and prognostic values for patients with myocarditis.

\section{Sarcoidosis}

Sarcoidosis is a multisystem granulomatous inflammatory disease. The clinical manifestations of cardiac sarcoidosis (CS) include conduction block, ventricular arrhythmias, and heart failure, although some patients may be asymptomatic [147,
148]. Cardiac symptoms may predominate in patients with no extra-cardiac manifestations. Cardiac complication was the second most common cause of death in patients with sarcoidosis in some studies [149].

CMR has been proved to be useful in the diagnosis of CS. Both the updated Japanese Ministry of Health and Welfare (JMHW) criteria and the Heart Rhythm Society (HRS) expert consensus statement contain LGE on CMR as one of the diagnostic criteria for CS $[150,151]$. The pattern of LGE in patients with CS was variable, including subepicardial, transmural, subendocardial, or mid-wall, often involving more than one segment, and basal and/or mid-ventricular septum are the most common locations [152-154] (Fig. 3o, p). RV involvement occurred in around $70 \%$ of LGE-positive patients [153]. In a larger study of 321 patients with biopsyproven sarcoidosis, the prevalence of cardiac sarcoidosis was nearly $30 \%$ using HRS criteria, and CMR was the most accurate diagnostic test (area under the curve: 0.984) [155]. Recently, a meta-analysis of pathological images in patients with sarcoidosis showed the frequent patterns of heart involvement are LV subepicardial, septal, LV multifocal, and RV free wall; isolated LV midmyocardial or isolated LV subendocardial involvement was never present [156]. These characteristic features may be helpful to interpret the CMR study.

CMR is useful to identify patients with sarcoidosis who are at risk of cardiac adverse outcomes. In a study of 81 patients with extra-cardiac sarcoidosis, patients with myocardial damage detected by LGE-CMR had a 9-fold higher rate of adverse events and an 11.5-fold higher rate of cardiac death compared with patients without LGE [153]. In another study enrolling 155 patients with systemic sarcoidosis who underwent CMR, the presence of LGE yielded $>30$-fold increased risk of death, aborted SCD, or appropriate ICD discharge [157]. LGE was the independent predictor of MACE in the study of $321 \mathrm{pa}-$ tients with biopsy-proven sarcoidosis [155]. In addition to LV LGE, decreased right ventricular ejection fraction (RVEF) and the presence of RV-LGE evaluated by CMR showed an increased risk of adverse outcomes [158, 159].

\section{Heart Transplantation}

Heart transplantation is a well-established treatment for select patients with end-stage heart failure. The outcomes of heart transplantation have significantly improved with advances in immunosuppressive therapy and management of complications. However, cardiac allograft rejection (CAR) and cardiac allograft vasculopathy (CAV) remain the significant causes of mortality in heart transplant recipients [160].

As acute cardiac allograft rejection (ACAR) is a main source of mortality in the early post-transplant period, timely and accurate diagnosis of allograft rejection is important in 
order to provide effective treatment. CMR is attractive for rejection surveillance due to its ability to characterize myocardial tissue. Different studies have shown a positive correlation between T2 mapping and CAR [161-163]. There is also evidence demonstrating native T1 is higher in patients with clinically significant rejection compared with patients with no or nonclinically significant rejection [164]. With multiparametric CMR, the combination of T2 and ECV increased the sensitivity for detection of ACAR [165]. CAV is an important factor of chronic graft failure [160], and it can be detected by CMRbased myocardial perfusion reserve [166].

\section{Valvular Heart Disease}

Primary valvular heart disease can cause HF, and secondary valve disease is common in heart failure. Echocardiography is the first-line imaging modality for the assessment of valve disease; however, the role of CMR is increasing as it allows for accurate quantification of regurgitant volumes in addition to quantification of ventricular volumes and assessment of myocardial fibrosis.

\section{Aortic Valve}

CMR has advantages in the assessment of aortic stenosis (AS) including the assessment of the anatomy of the valve and the aortic root and the measurement of stenotic jet velocity [167]. Fibrosis is an important marker of LV remodeling response during AS progression [168]. Meta-analysis showed LGE was an independent predictor of mortality $[169,170]$. ECV was also used to quantify fibrosis in AS patients, and ECV was associated with mortality after adjusting other factors such as EF and LGE [171]. CMR is a reliable modality to assess aortic annulus dimensions in patients with pre-transcatheter aortic valve replacement, especially for patients who are not suitable to receive CT contrast $[172,173]$.

CMR is capable to quantify aortic regurgitation (AR) severity by determining the aortic regurgitant volume and assess aorta for potential etiology (Fig. 4). Accurate assessment of AR after TAVR is crucial as post-procedure AR is associated with worse outcomes [174]. Regurgitant fraction measured by CMR following TAVR had a greater association with mortality and heart failure hospitalization when compared with echocardiography [175].

\section{Mitral Valve}

CMR can provide valuable complementary information to echocardiography by the quantitative measurement of ventricular and atrial volume and mitral regurgitation (MR) volume [176]. MR can result in a spectrum of myocardial fibrosis which has been detected by LGE $[177,178]$. The expansion of ECV detected by CMR in patients with chronic asymptomatic moderate or severe primary degenerative MR was associated with impaired LV function and reduced exercise capacity [179]. How best to identify suitable patients for early surgical intervention remains controversial. A prospective multicenter study showed the discriminatory ability of CMR quantification of MR (regurgitant volume $>55 \mathrm{~mL}$ or regurgitant fraction $>40 \%$ ) for identifying patients who progressed to symptoms or other indications for surgery [180]. In another study, the CMR-derived regurgitant volume showed better discriminative power to predict mortality than other imaging parameters [181].

\section{Pericardial Disease}

Constrictive pericarditis can cause right-sided heart failure and is often difficult to diagnose. CMR can image interventricular dependency using real-time free breathing cine techniques. Myocardial tagging can qualitatively assess the adherence of the myocardium and constricted pericardium [182, 183]. LGE imaging of the pericardium can indicate myocardial inflammation and fibrosis [184]. CMR may recognize patients with pericarditis at higher risk of adverse events such as recurrences and constrictive pericarditis by assessing pericardial thickening, edema, and/or fibrosis [185].

\section{Pulmonary Artery Hypertension and Right Ventricular Failure}

Right ventricular failure is a complex clinical problem and usually associated with poor prognosis. RV function can be affected by pressure overload, volume overload, and contractility failure (such as infarction, myocarditis, or ARVC) [186]. Pulmonary hypertension (PH) increases afterload of the right ventricle and leads to abnormal RV structure and function. RV function is a major prognostic determinant for patients with PH. CMR provides valuable information on RV morphology, volumes, function, and mass for patients with PH. A metaanalysis demonstrated RVEF detected by CMR was the strongest predictor of mortality in $\mathrm{PAH}$ [187]. RV/LV volume ratio is also a sensitive marker for $\mathrm{RV}$ dilation with $\mathrm{RV} / \mathrm{LV}$ volume ratio $>2.3$ associated with increased mortality in patients with $\mathrm{PH}$ [188]. The LGE in PH often occurs in RV insertion sites and is associated with reduced regional longitudinal contractility at the base $[189,190]$. The significance of LGE in PH patients has not been fully elucidated. A study demonstrated patients with RV insertion point LGE had larger right ventricular volume index and lower RVEF; however, multivariate analysis showed mean pulmonary artery pressure (PAP), exercise metabolic equivalents, and RVEF were significant predictors of mortality, not LGE [191]. 


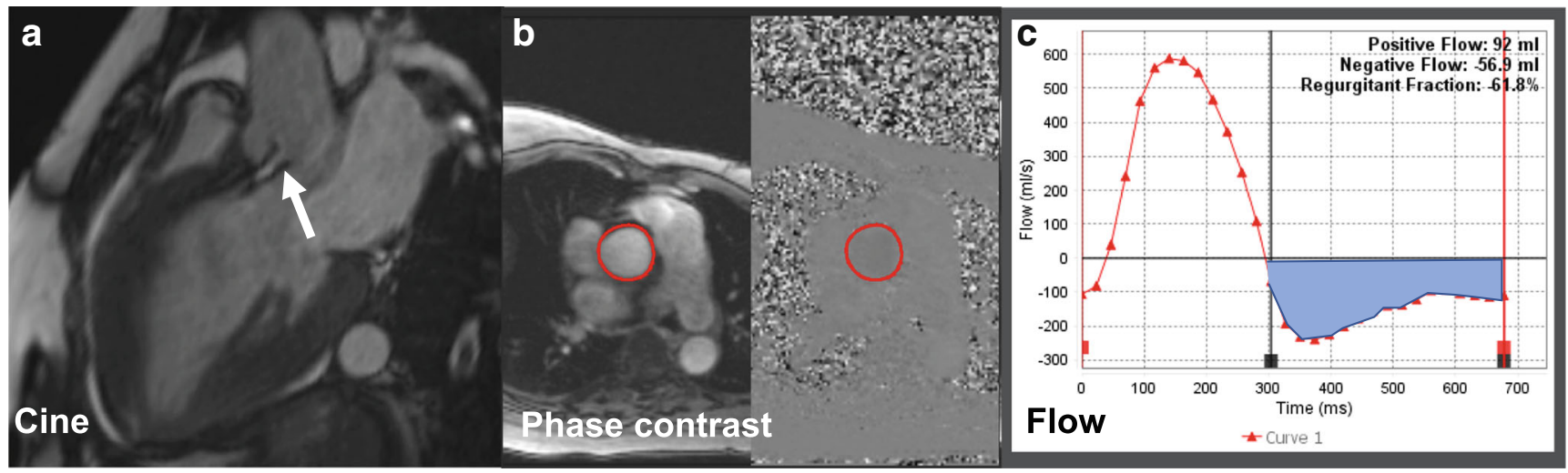

Fig. 4 Valvular disease example: aortic regurgitation. a Left ventricular outflow tract view in diastole showing aortic regurgitation jet (arrow) in a 56-year-old woman presented with heart failure. b Aortic through-plane phase contrast with magnitude and phase images of the same patient. c
Aortic flow curve demonstrating quantitative analysis of forward aortic flow and regurgitant flow as negative flow persisted through the entire diastole (shaded area). This was post-processed from the phase contrast images (b)

\section{Guiding Ablation}

Atrial fibrillation (AF) and $\mathrm{HF}$ often coexist and increase mortality risk. Studies showed that AF ablation reduced all-cause mortality and HF hospitalizations compared with drug therapy [192, 193]. Left atrial (LA) fibrosis is an important pathological change in the development of AF. The extent of a trial fibrosis assessed by LGE-CMR increased the likelihood of recurrent AF [194]. LV fibrosis may be a predictor of AF recurrence $[195,196]$. CMR is a potentially useful tool to guide repeated PV isolation by localizing conduction gaps [197].

Ventricular arrhythmias are common in patients with HF. ICD implantation is an effective way to prevent SCD in patients with HF. Catheter ablation has proved to be successful at preventing recurrent ventricular tachycardia (VT). Different studies demonstrated that CMR was helpful in guiding VT ablation by localizing VT substrates [198-200]. Identifying endocardial or epicardial VT origin is useful to plan the ablation approach in advance [198]. In the future, MR-guided electrophysiological procedures may provide the opportunity for real-time assessments of arrhythmia substrate and ablation guidance [201].

\section{Conclusion}

CMR has evolved into a major non-invasive imaging tool to guide the diagnosis, risk stratification, and management for patients with HF. It can assess cardiac structure and function accurately and reproducibly. Its ability to characterize myocardial tissue can help determine the underlying etiology of HF. CMR will play a greater role in the field of $\mathrm{HF}$ as more outcome data accumulate.

\section{Declaration}

Conflict of Interest Chuanfen Liu declares no conflicts of interest.

Victor A. Ferrari reports grant support from the NIH; he is on the Senior Advisory Board for the Journal of Cardiovascular Magnetic Resonance and reports other from Inteleos Inc. and the Society for Cardiovascular Magnetic Resonance.

Yuchi Han reports grant support from the NIH and Pfizer and personal fees from GE, and she is also an Associate Editor for the Journal of Cardiovascular Magnetic Resonance.

Human and Animal Rights and Informed Consent This article does not contain any studies with human or animal subjects performed by any of the authors.

\section{References}

Papers of particular interest, published recently, have been highlighted as:

- Of importance

• Of major importance

1. Yancy CW, Jessup M, Bozkurt B, Butler J, Casey DE Jr, Drazner $\mathrm{MH}$, et al. (2013) ACCF/AHA guideline for the management of heart failure: a report of the American College of Cardiology Foundation/American Heart Association Task Force on Practice Guidelines. J Am Coll Cardiol. 2013;62(16):e147-239. https:// doi.org/10.1016/j.jacc.2013.05.019.

2. Ponikowski P, Voors AA, Anker SD, Bueno H, Cleland JGF, Coats AJS, et al. (2016) ESC guidelines for the diagnosis and treatment of acute and chronic heart failure: the task force for the diagnosis and treatment of acute and chronic heart failure of the European Society of Cardiology (ESC). Developed with the special contribution of the Heart Failure Association (HFA) of the ESC. Eur Heart J. 2016;37(27):2129-200. https://doi.org/10. 1093/eurheartj/ehw128.

3. Virani SS, Alonso A, Benjamin EJ, Bittencourt MS, Callaway CW, Carson AP, et al. Heart disease and stroke statistics-2020 update: a report from the American Heart Association. 
Circulation. 2020; CIR0000000000000757. https://doi.org/10. 1161/CIR.0000000000000757

4. Ziaeian B, Fonarow GC. Epidemiology and aetiology of heart failure. Nat Rev Cardiol. 2016;13(6):368-78. https://doi.org/10. 1038/nrcardio.2016.25.

5. Bing R, Dweck MR. Myocardial fibrosis: why image, how to image and clinical implications. Heart. 2019;105(23):1832-40. https://doi.org/10.1136/heartjnl-2019-315560.

6. Messroghli DR, Moon JC, Ferreira VM, Grosse-Wortmann L, He $\mathrm{T}$, Kellman P, et al. Clinical recommendations for cardiovascular magnetic resonance mapping of $\mathrm{T} 1, \mathrm{~T} 2, \mathrm{~T} 2 *$ and extracellular volume: a consensus statement by the Society for Cardiovascular Magnetic Resonance (SCMR) endorsed by the European Association for Cardiovascular Imaging (EACVI). J Cardiovasc Magn Reson. 2017;19(1):75. https://doi.org/10.1186/s12968-0170389-8.

7. Patel MR, White RD, Abbara S, Bluemke DA, Herfkens RJ, Picard M, et al. (2013) ACCF/ACR/ASE/ASNC/SCCT/SCMR appropriate utilization of cardiovascular imaging in heart failure: a joint report of the American College of Radiology Appropriateness Criteria Committee and the American College of Cardiology Foundation Appropriate Use Criteria Task Force. J Am Coll Cardiol. 2013;61(21):2207-31. https://doi.org/10. 1016/j.jacc.2013.02.005.

8. Lota AS, Gatehouse PD, Mohiaddin RH. T2 mapping and T2* imaging in heart failure. Heart Fail Rev. 2017;22(4):431-40. https://doi.org/10.1007/s10741-017-9616-5.

9. Robinson AA, Chow K, Salerno M. Myocardial T1 and ECV measurement: underlying concepts and technical considerations. JACC Cardiovasc Imaging. 2019;12(11 Pt 2):2332-44. https:// doi.org/10.1016/j.jcmg.2019.06.031.

10. Moon JC, Messroghli DR, Kellman P, Piechnik SK, Robson MD, Ugander M, et al. Myocardial T1 mapping and extracellular volume quantification: a Society for Cardiovascular Magnetic Resonance (SCMR) and CMR Working Group of the European Society of Cardiology consensus statement. J Cardiovasc Magn Reson. 2013;15(1):92. https://doi.org/10.1186/1532-429X-15-92.

11. Abbasi SA, Ertel A, Shah RV, Dandekar V, Chung J, Bhat G, et al. Impact of cardiovascular magnetic resonance on management and clinical decision-making in heart failure patients. J Cardiovasc Magn Reson. 2013;15(1):89. https://doi.org/10.1186/1532429X-15-89.

12. Kim RJ, Fieno DS, Parrish TB, Harris K, Chen EL, Simonetti O, et al. Relationship of MRI delayed contrast enhancement to irreversible injury, infarct age, and contractile function. Circulation. 1999;100(19):1992-2002. https://doi.org/10.1161/01.cir.100.19. 1992.

13. Mahrholdt H, Wagner A, Judd RM, Sechtem U, Kim RJ. Delayed enhancement cardiovascular magnetic resonance assessment of non-ischaemic cardiomyopathies. Eur Heart J. 2005;26(15): 1461-74. https://doi.org/10.1093/eurheartj/ehi258.

14. Flett AS, Shambrook J, Adam RD. The prognostic role of tissue characterisation using cardiovascular magnetic resonance in heart failure. Cardiac Fail Rev. 2017;3(2):86-96. https://doi.org/10. 15420/cfr.2017:19:1

15. Kim RJ, Albert TS, Wible JH, Elliott MD, Allen JC, Lee JC, et al. Performance of delayed-enhancement magnetic resonance imaging with gadoversetamide contrast for the detection and assessment of myocardial infarction: an international, multicenter, double-blinded, randomized trial. Circulation. 2008;117(5):629-37. https://doi.org/10.1161/CIRCULATIONAHA.107.723262.

16. Soriano CJ, Ridocci F, Estornell J, Jimenez J, Martinez V, De Velasco JA. Noninvasive diagnosis of coronary artery disease in patients with heart failure and systolic dysfunction of uncertain etiology, using late gadolinium-enhanced cardiovascular magnetic resonance. J Am Coll Cardiol. 2005;45(5):743-8. https://oi.org/ 10.1016/j.jacc.2004.11.037.

17. Casolo G, Minneci S, Manta R, Sulla A, Del Meglio J, Rega L, et al. Identification of the ischemic etiology of heart failure by cardiovascular magnetic resonance imaging: diagnostic accuracy of late gadolinium enhancement. Am Heart J. 2006;151(1):101-8. https://doi.org/10.1016/j.ahj.2005.03.068.

18. Schwitter J, Wacker CM, van Rossum AC, Lombardi M, Al-Saadi $\mathrm{N}$, Ahlstrom H, et al. MR-IMPACT: comparison of perfusioncardiac magnetic resonance with single-photon emission computed tomography for the detection of coronary artery disease in a multicentre, multivendor, randomized trial. Eur Heart J. 2008;29(4):480-9. https://doi.org/10.1093/eurheartj/ehm617.

19. Schwitter J, Wacker CM, Wilke N, Al-Saadi N, Sauer E, Huettle $\mathrm{K}$, et al. MR-IMPACT II: Magnetic Resonance Imaging for Myocardial Perfusion Assessment in Coronary artery disease Trial: perfusion-cardiac magnetic resonance vs. single-photon emission computed tomography for the detection of coronary artery disease: a comparative multicentre, multivendor trial. Eur Heart J. 2013;34(10):775-81. https://doi.org/10.1093/eurheartj/ ehs022.

20. Greenwood JP, Maredia N, Younger JF, Brown JM, Nixon J, Everett CC, et al. Cardiovascular magnetic resonance and singlephoton emission computed tomography for diagnosis of coronary heart disease (CE-MARC): a prospective trial. Lancet. 2012;379(9814):453-60. https://doi.org/10.1016/S01406736(11)61335-4.

21. Kwong RY, Ge Y, Steel K, Bingham S, Abdullah S, Fujikura K, et al. Cardiac magnetic resonance stress perfusion imaging for evaluation of patients with chest pain. J Am Coll Cardiol. 2019;74(14):1741-55. https://doi.org/10.1016/j.jacc.2019.07. 074.

22. Gulati A, Japp AG, Raza S, Halliday BP, Jones DA, Newsome S, et al. Absence of myocardial fibrosis predicts favorable long-term survival in new-onset heart failure. Circ Cardiovasc Imaging. 2018;11(9):e007722 https://doi.org/10.1161/CIRCIMAGING. 118.007722 .

23. Udelson JE. Cardiac magnetic resonance imaging for long-term prognosis in heart failure. Circ Cardiovasc Imaging. 2018;11(9): e008264. https://doi.org/10.1161/CIRCIMAGING.118.008264.

24. Wu E, Ortiz JT, Tejedor P, Lee DC, Bucciarelli-Ducci C, Kansal $\mathrm{P}$, et al. Infarct size by contrast enhanced cardiac magnetic resonance is a stronger predictor of outcomes than left ventricular ejection fraction or end-systolic volume index: prospective cohort study. Heart. 2008;94(6):730-6. https://doi.org/10.1136/hrt.2007. 122622.

25. Assomull RG, Prasad SK, Lyne J, Smith G, Burman ED, Khan M, et al. Cardiovascular magnetic resonance, fibrosis, and prognosis in dilated cardiomyopathy. J Am Coll Cardiol. 2006;48(10):197785. https://doi.org/10.1016/j.jacc.2006.07.049.

26. Mrsic Z, Mousavi N, Hulten E, Bittencourt MS. The prognostic value of late gadolinium enhancement in nonischemic heart disease. Magn Reson Imaging Clin N Am. 2019;27(3):545-61. https://doi.org/10.1016/j.mric.2019.04.010.

27. Kelle S, Roes SD, Klein C, Kokocinski T, de Roos A, Fleck E, et al. Prognostic value of myocardial infarct size and contractile reserve using magnetic resonance imaging. J Am Coll Cardiol. 2009;54(19):1770-7. https://doi.org/10.1016/j.jacc.2009.07.027.

28. El Aidi H, Adams A, Moons KG, Den Ruijter HM, Mali WP, Doevendans PA, et al. Cardiac magnetic resonance imaging findings and the risk of cardiovascular events in patients with recent myocardial infarction or suspected or known coronary artery disease: a systematic review of prognostic studies. J Am Coll Cardiol. 2014;63(11):1031-45. https://doi.org/10.1016/j.jacc.2013.11. 048. 
29. Kwon DH, Halley CM, Carrigan TP, Zysek V, Popovic ZB, Setser $\mathrm{R}$, et al. Extent of left ventricular scar predicts outcomes in ischemic cardiomyopathy patients with significantly reduced systolic function: a delayed hyperenhancement cardiac magnetic resonance study. JACC Cardiovasc Imaging. 2009;2(1):34-44. https://doi.org/10.1016/j.jcmg.2008.09.010.

30. Puntmann VO, Carr-White G, Jabbour A, Yu CY, Gebker R, Kelle S, et al. Native T1 and ECV of noninfarcted myocardium and outcome in patients with coronary artery disease. J Am Coll Cardiol. 2018;71(7):766-78. https://doi.org/10.1016/j.jacc.2017. 12.020 .

31. Carberry J, Carrick D, Haig C, Ahmed N, Mordi I, McEntegart M, et al. Persistent iron within the infarct core after ST-segment elevation myocardial infarction: implications for left ventricular remodeling and health outcomes. JACC Cardiovasc Imaging. 2018;11(9):1248-56. https://doi.org/10.1016/j.jcmg.2017.08.027.

32. Hamirani YS, Wong A, Kramer CM, Salerno M. Effect of microvascular obstruction and intramyocardial hemorrhage by CMR on LV remodeling and outcomes after myocardial infarction: a systematic review and meta-analysis. JACC Cardiovasc Imaging. 2014;7(9):940-52. https://doi.org/10.1016/j.jcmg.2014.06.012.

33. Wu KC, Zerhouni EA, Judd RM, Lugo-Olivieri CH, Barouch LA, Schulman SP, et al. Prognostic significance of microvascular obstruction by magnetic resonance imaging in patients with acute myocardial infarction. Circulation. 1998;97(8):765-72. https:// doi.org/10.1161/01.cir.97.8.765.

34. de Waha S, Patel MR, Granger CB, Ohman EM, Maehara A, Eitel I, et al. Relationship between microvascular obstruction and adverse events following primary percutaneous coronary intervention for ST-segment elevation myocardial infarction: an individual patient data pooled analysis from seven randomized trials. Eur Heart J. 2017;38(47):3502-10. https://doi.org/10.1093/eurheartj/ ehx414.

35. Nijveldt R, Hofman MB, Hirsch A, Beek AM, Umans VA, Algra $\mathrm{PR}$, et al. Assessment of microvascular obstruction and prediction of short-term remodeling after acute myocardial infarction: cardiac MR imaging study. Radiology. 2009;250(2):363-70. https://doi. org/10.1148/radiol.2502080739.

36. Bulluck H, Rosmini S, Abdel-Gadir A, Bhuva AN, Treibel TA, Fontana M, et al. Diagnostic performance of T1 and T2 mapping to detect intramyocardial hemorrhage in reperfused ST-segment elevation myocardial infarction (STEMI) patients. J Magn Reson Imaging. 2017;46(3):877-86. https://doi.org/10.1002/jmri.25638.

37. Selvanayagam JB, Kardos A, Francis JM, Wiesmann F, Petersen SE, Taggart DP, et al. Value of delayed-enhancement cardiovascular magnetic resonance imaging in predicting myocardial viability after surgical revascularization. Circulation. 2004;110(12): 1535-41. https://doi.org/10.1161/01.CIR.0000142045.22628.74.

38. Liu D, Borlotti A, Viliani D, Jerosch-Herold M, Alkhalil M, De Maria GL, et al. CMR native T1 mapping allows differentiation of reversible versus irreversible myocardial damage in ST-segmentelevation myocardial infarction: an OxAMI Study (Oxford Acute Myocardial Infarction). Circ Cardiovasc Imaging. 2017;10(8): e005986. https://doi.org/10.1161/CIRCIMAGING.116.005986.

39. Jamiel A, Ebid M, Ahmed AM, Ahmed D, Al-Mallah MH. The role of myocardial viability in contemporary cardiac practice. Heart Fail Rev. 2017;22(4):401-13. https://doi.org/10.1007/ s10741-017-9626-3.

40. Anavekar NS, Chareonthaitawee P, Narula J, Gersh BJ. Revascularization in patients with severe left ventricular dysfunction: is the assessment of viability still viable? J Am Coll Cardiol. 2016;67(24):2874-87. https://doi.org/10.1016/j.jacc.2016.03. 571.

41. Romero J, Xue X, Gonzalez W, Garcia MJ. CMR imaging assessing viability in patients with chronic ventricular dysfunction due to coronary artery disease: a meta-analysis of prospective trials. JACC Cardiovasc Imaging. 2012;5(5):494-508. https:// doi.org/10.1016/j.jcmg.2012.02.009.

42. Kim RJ, Wu E, Rafael A, Chen EL, Parker MA, Simonetti O, et al. The use of contrast-enhanced magnetic resonance imaging to identify reversible myocardial dysfunction. N Engl J Med. 2000;343(20):1445-53. https://doi.org/10.1056/ nejm200011163432003.

43. Kwon DH, Obuchowski NA, Marwick TH, Menon V, Griffin B, Flamm SD, et al. Jeopardized myocardium defined by late gadolinium enhancement magnetic resonance imaging predicts survival in patients with ischemic cardiomyopathy: impact of revascularization. J Am Heart Assoc. 2018;7(22):e009394. https://doi. org/10.1161/JAHA.118.009394.

44. Hershberger RE, Hedges DJ, Morales A. Dilated cardiomyopathy: the complexity of a diverse genetic architecture. Nat Rev Cardiol. 2013;10(9):531-47. https://doi.org/10.1038/nrcardio.2013.105.

45. Bondue A, Arbustini E, Bianco A, Ciccarelli M, Dawson D, De Rosa M, et al. Complex roads from genotype to phenotype in dilated cardiomyopathy: scientific update from the Working Group of Myocardial Function of the European Society of Cardiology. Cardiovasc Res. 2018;114(10):1287-303. https:// doi.org/10.1093/cvr/cvy122.

46. McCrohon JA, Moon JC, Prasad SK, McKenna WJ, Lorenz CH, Coats AJ, et al. Differentiation of heart failure related to dilated cardiomyopathy and coronary artery disease using gadoliniumenhanced cardiovascular magnetic resonance. Circulation. 2003;108(1):54-9. https://doi.org/10.1161/01.CIR.0000078641. 19365.4C.

47. Halliday BP, Gulati A, Ali A, Guha K, Newsome S, Arzanauskaite M, et al. Association between midwall late gadolinium enhancement and sudden cardiac death in patients with dilated cardiomyopathy and mild and moderate left ventricular systolic dysfunction. Circulation. 2017;135(22):2106-15. https://doi.org/10.1161/CIRCULATIONAHA.116.026910.

48. Halliday BP, Baksi AJ, Gulati A, Ali A, Newsome S, Izgi C, et al. Outcome in dilated cardiomyopathy related to the extent, location, and pattern of late gadolinium enhancement. JACC Cardiovasc Imaging. 2019;12(8 Pt 2):1645-55. https://doi.org/10.1016/j. jcmg.2018.07.015.

49. Gulati A, Jabbour A, Ismail TF, Guha K, Khwaja J, Raza S, et al. Association of fibrosis with mortality and sudden cardiac death in patients with nonischemic dilated cardiomyopathy. JAMA. 2013;309(9):896-908. https://doi.org/10.1001/jama.2013.1363.

50. Te Rijdt WP, Ten Sande JN, Gorter TM, van der Zwaag PA, van Rijsingen IA, Boekholdt SM, et al. Myocardial fibrosis as an early feature in phospholamban p.Arg14del mutation carriers: phenotypic insights from cardiovascular magnetic resonance imaging. Eur Heart J Cardiovasc Imaging. 2019;20(1):92-100. https://doi. org/10.1093/ehjci/jey047.

51. Flett AS, Hayward MP, Ashworth MT, Hansen MS, Taylor AM, Elliott PM, et al. Equilibrium contrast cardiovascular magnetic resonance for the measurement of diffuse myocardial fibrosis: preliminary validation in humans. Circulation. 2010;122(2):138 44. https://doi.org/10.1161/CIRCULATIONAHA.109.930636.

52. Messroghli DR, Nordmeyer S, Dietrich T, Dirsch O, Kaschina E, Savvatis K, et al. Assessment of diffuse myocardial fibrosis in rats using small-animal Look-Locker inversion recovery T1 mapping. Circ Cardiovasc Imaging. 2011;4(6):636-40. https://doi.org/10. 1161/CIRCIMAGING.111.966796.

53. Aus dem Siepen F, Buss SJ, Messroghli D, Andre F, Lossnitzer D, Seitz S, et al. T1 mapping in dilated cardiomyopathy with cardiac magnetic resonance: quantification of diffuse myocardial fibrosis and comparison with endomyocardial biopsy. Eur Heart J Cardiovasc Imaging. 2015;16(2):210-6. https://doi.org/10.1093/ ehjci/jeu183. 
54. Disertori M, Rigoni M, Pace N, Casolo G, Mase M, Gonzini L, et al. Myocardial fibrosis assessment by LGE is a powerful predictor of ventricular tachyarrhythmias in ischemic and nonischemic LV dysfunction: a meta-analysis. JACC Cardiovasc Imaging. 2016;9(9):1046-55. https://doi.org/10.1016/j.jcmg. 2016.01.033.

55. Amzulescu MS, Rousseau MF, Ahn SA, Boileau L, de Meester de Ravenstein C, Vancraeynest D, et al. Prognostic impact of hypertrabeculation and noncompaction phenotype in dilated cardiomyopathy: A CMR Study. JACC Cardiovasc Imaging. 2015;8(8):934-46. https://doi.org/10.1016/j.jcmg.2015.04.015.

56. Sree Raman K, Nucifora G, Leong DP, Marx C, Shah R, Woodman RJ, et al. Long term prognostic importance of late gadolinium enhancement in first-presentation non-ischaemic dilated cardiomyopathy. Int J Cardiol. 2019;280:124-9. https://doi. org/10.1016/j.ijcard.2019.01.018.

57. Becker MAJ, Cornel JH, van de Ven PM, van Rossum AC, Allaart $\mathrm{CP}$, Germans T. The prognostic value of late gadoliniumenhanced cardiac magnetic resonance imaging in nonischemic dilated cardiomyopathy: a review and meta-analysis. JACC Cardiovasc Imaging. 2018;11(9):1274-84. https://doi.org/10. 1016/j.jcmg.2018.03.006.

58. Puntmann VO, Carr-White G, Jabbour A, Yu CY, Gebker R, Kelle S, et al. T1-mapping and outcome in nonischemic cardiomyopathy: all-cause mortality and heart failure. JACC Cardiovasc Imaging. 2016;9(1):40-50. https://doi.org/10.1016/j.jcmg.2015. 12.001 .

59. Schuster A, Hor KN, Kowallick JT, Beerbaum P, Kutty S. Cardiovascular magnetic resonance myocardial feature tracking: concepts and clinical applications. Circ Cardiovasc Imaging. 2016;9(4):e004077. https://doi.org/10.1161/CIRCIMAGING. 115.004077 .

60. Buss SJ, Breuninger K, Lehrke S, Voss A, Galuschky C, Lossnitzer D, et al. Assessment of myocardial deformation with cardiac magnetic resonance strain imaging improves risk stratification in patients with dilated cardiomyopathy. Eur Heart J Cardiovasc Imaging. 2015;16(3):307-15. https://doi.org/10. 1093/ehjci/jeu181.

61. Bello D, Shah DJ, Farah GM, Di Luzio S, Parker M, Johnson MR, et al. Gadolinium cardiovascular magnetic resonance predicts reversible myocardial dysfunction and remodeling in patients with heart failure undergoing beta-blocker therapy. Circulation. 2003;108(16):1945-53. https://doi.org/10.1161/01.CIR. 0000095029.57483 .60

62. Leong DP, Chakrabarty A, Shipp N, Molaee P, Madsen PL, Joerg L, et al. Effects of myocardial fibrosis and ventricular dyssynchrony on response to therapy in new-presentation idiopathic dilated cardiomyopathy: insights from cardiovascular magnetic resonance and echocardiography. Eur Heart J. 2012;33(5): 640-8. https://doi.org/10.1093/eurheartj/ehr391.

63. Kida K, Yoneyama K, Kobayashi Y, Takano M, Akashi YJ, Miyake F. Late gadolinium enhancement on cardiac magnetic resonance images predicts reverse remodeling in patients with nonischemic cardiomyopathy treated with carvedilol. Int $\mathrm{J}$ Cardiol. 2013;168(2):1588-9. https://doi.org/10.1016/j.ijcard. 2013.01.043.

64. Stecker EC, Vickers C, Waltz J, Socoteanu C, John BT, Mariani $\mathrm{R}$, et al. Population-based analysis of sudden cardiac death with and without left ventricular systolic dysfunction: two-year findings from the Oregon Sudden Unexpected Death Study. J Am Coll Cardiol. 2006;47(6):1161-6. https://doi.org/10.1016/j.jacc.2005. 11.045 .

65. de Bakker JM, van Capelle FJ, Janse MJ, Wilde AA, Coronel R, Becker AE, et al. Reentry as a cause of ventricular tachycardia in patients with chronic ischemic heart disease: electrophysiologic and anatomic correlation. Circulation. 1988;77(3):589-606. https://doi.org/10.1161/01.cir.77.3.589.

66. Soejima K, Stevenson WG, Sapp JL, Selwyn AP, Couper G, Epstein LM. Endocardial and epicardial radiofrequency ablation of ventricular tachycardia associated with dilated cardiomyopathy: the importance of low-voltage scars. J Am Coll Cardiol. 2004;43(10):1834-42. https://doi.org/10.1016/j.jacc.2004.01. 029.

67. Chan RH, Maron BJ, Olivotto I, Pencina MJ, Assenza GE, Haas $\mathrm{T}$, et al. Prognostic value of quantitative contrast-enhanced cardiovascular magnetic resonance for the evaluation of sudden death risk in patients with hypertrophic cardiomyopathy. Circulation. 2014;130(6):484-95. https://doi.org/10.1161/ CIRCULATIONAHA.113.007094.

68. Di Marco A, Anguera I, Schmitt M, Klem I, Neilan TG, White JA, et al. Late gadolinium enhancement and the risk for ventricular arrhythmias or sudden death in dilated cardiomyopathy: systematic review and meta-analysis. JACC Heart Fail. 2017;5(1):28-38. https://doi.org/10.1016/j.jchf.2016.09.017.

69. Klem I, Weinsaft JW, Bahnson TD, Hegland D, Kim HW, Hayes $\mathrm{B}$, et al. Assessment of myocardial scarring improves risk stratification in patients evaluated for cardiac defibrillator implantation. J Am Coll Cardiol. 2012;60(5):408-20. https://doi.org/10.1016/j. jacc.2012.02.070.

70. Leclercq C, Kass DA. Retiming the failing heart: principles and current clinical status of cardiac resynchronization. J Am Coll Cardiol. 2002;39(2):194-201. https://doi.org/10.1016/s07351097(01)01747-8.

71. Abraham WT, Fisher WG, Smith AL, Delurgio DB, Leon AR, Loh E, et al. Cardiac resynchronization in chronic heart failure. N Engl J Med. 2002;346(24):1845-53. https://doi.org/10.1056/ NEJMoa013168.

72. White JA, Yee R, Yuan X, Krahn A, Skanes A, Parker M, et al. Delayed enhancement magnetic resonance imaging predicts response to cardiac resynchronization therapy in patients with intraventricular dyssynchrony. J Am Coll Cardiol. 2006;48(10):195360. https://doi.org/10.1016/j.jacc.2006.07.046.

73. Bleeker GB, Kaandorp TA, Lamb HJ, Boersma E, Steendijk P, de Roos A, et al. Effect of posterolateral scar tissue on clinical and echocardiographic improvement after cardiac resynchronization therapy. Circulation. 2006;113(7):969-76. https://doi.org/10. 1161/CIRCULATIONAHA.105.543678.

74. Bilchick KC, Kuruvilla S, Hamirani YS, Ramachandran R, Clarke SA, Parker KM, et al. Impact of mechanical activation, scar, and electrical timing on cardiac resynchronization therapy response and clinical outcomes. J Am Coll Cardiol. 2014;63(16):165766. https://doi.org/10.1016/j.jacc.2014.02.533.

75. Maron MS, Maron BJ, Harrigan C, Buros J, Gibson CM, Olivotto I, et al. Hypertrophic cardiomyopathy phenotype revisited after 50 years with cardiovascular magnetic resonance. J Am Coll Cardiol. 2009;54(3):220-8. https://doi.org/10.1016/j.jacc.2009.05.006.

76. Maron BJ, Maron MS. The remarkable 50 years of imaging in $\mathrm{HCM}$ and how it has changed diagnosis and management: from M-mode echocardiography to CMR. JACC Cardiovasc Imaging. 2016;9(7):858-72. https://doi.org/10.1016/j.jcmg.2016.05.003.

77. Maron MS. Clinical utility of cardiovascular magnetic resonance in hypertrophic cardiomyopathy. J Cardiovasc Magn Reson. 2012;14(1):13. https://doi.org/10.1186/1532-429X-14-13.

78. Rudolph A, Abdel-Aty H, Bohl S, Boye P, Zagrosek A, Dietz R, et al. Noninvasive detection of fibrosis applying contrastenhanced cardiac magnetic resonance in different forms of left ventricular hypertrophy relation to remodeling. J Am Coll Cardiol. 2009;53(3):284-91. https://doi.org/10.1016/j.jacc.2008. 08.064 .

79. Valente AM, Lakdawala NK, Powell AJ, Evans SP, Cirino AL, Orav EJ, et al. Comparison of echocardiographic and cardiac 
magnetic resonance imaging in hypertrophic cardiomyopathy sarcomere mutation carriers without left ventricular hypertrophy. Circ Cardiovasc Genet. 2013;6(3):230-7. https://doi.org/10. 1161/CIRCGENETICS.113.000037.

80. Wang J, Wan K, Sun J, Li W, Liu H, Han Y, et al. Phenotypic diversity identified by cardiac magnetic resonance in a large hypertrophic cardiomyopathy family with a single MYH7 mutation. Sci Rep. 2018;8(1):973. https://doi.org/10.1038/s41598-01819372-4.

81. Weissler-Snir A, Hindieh W, Gruner C, Fourey D, Appelbaum E, Rowin E, et al. Lack of phenotypic differences by cardiovascular magnetic resonance imaging in MYH7 (beta-myosin heavy chain)- versus MYBPC3 (myosin-binding protein C)-related hypertrophic cardiomyopathy. Circ Cardiovasc Imaging. 2017;10(2):e005311. https://doi.org/10.1161/CIRCIMAGING. 116.005311 .

82. Miller RJH, Heidary S, Pavlovic A, Schlachter A, Dash R, Fleischmann D, et al. Defining genotype-phenotype relationships in patients with hypertrophic cardiomyopathy using cardiovascular magnetic resonance imaging. PLoS One. 2019;14(6): e0217612. https://doi.org/10.1371/journal.pone.0217612.

83. Maron MS, Rowin EJ. The role of cardiac MRI in the diagnosis and risk stratification of hypertrophic cardiomyopathy. Arrhythmia Electrophysiol Rev. 2016;5(3):197. https://doi.org/ 10.15420/aer.2016:13:3.

84. van de Schoor FR, Aengevaeren VL, Hopman MT, Oxborough DL, George KP, Thompson PD, et al. Myocardial fibrosis in athletes. Mayo Clin Proc. 2016;91(11):1617-31. https://doi.org/10. 1016/j.mayocp.2016.07.012

85. Caselli S, Maron MS, Urbano-Moral JA, Pandian NG, Maron BJ, Pelliccia A. Differentiating left ventricular hypertrophy in athletes from that in patients with hypertrophic cardiomyopathy. Am J Cardiol. 2014;114(9):1383-9. https://doi.org/10.1016/j.amjcard. 2014.07.070

86. Swoboda PP, McDiarmid AK, Erhayiem B, Broadbent DA, Dobson LE, Garg P, et al. Assessing myocardial extracellular volume by T1 mapping to distinguish hypertrophic cardiomyopathy from athlete's heart. J Am Coll Cardiol. 2016;67(18):218990. https://doi.org/10.1016/j.jacc.2016.02.054.

87. Pujadas S, Donate M, Li CH, Merchan S, Cabanillas A, Alomar X, et al. Myocardial remodelling and tissue characterisation by cardiovascular magnetic resonance (CMR) in endurance athletes. BMJ Open Sport Exerc Med. 2018;4(1):e000422. https://doi.org/ 10.1136/bmjsem-2018-000422.

88. Malek LA, Barczuk-Falecka M, Werys K, Czajkowska A, Mroz A, Witek K, et al. Cardiovascular magnetic resonance with parametric mapping in long-term ultra-marathon runners. Eur J Radiol. 2019;117:89-94. https://doi.org/10.1016/j.ejrad.2019.06.001.

89. Janardhanan R, Kramer CM. Imaging in hypertensive heart disease. Expert Rev Cardiovasc Ther. 2011;9(2):199-209. https:// doi.org/10.1586/erc.10.190.

90. Kuruvilla S, Janardhanan R, Antkowiak P, Keeley EC, Adenaw $\mathrm{N}$, Brooks J, et al. Increased extracellular volume and altered mechanics are associated with LVH in hypertensive heart disease, not hypertension alone. JACC Cardiovasc Imaging. 2015;8(2): 172-80. https://doi.org/10.1016/j.jcmg.2014.09.020.

91. Treibel TA, Zemrak F, Sado DM, Banypersad SM, White SK, Maestrini V, et al. Extracellular volume quantification in isolated hypertension - changes at the detectable limits? J Cardiovasc Magn Reson. 2015;17(1):74. https://doi.org/10.1186/s12968015-0176-3.

92. Hinojar R, Varma N, Child N, Goodman B, Jabbour A, Yu CY, et al. T1 Mapping in discrimination of hypertrophic phenotypes: hypertensive heart disease and hypertrophic cardiomyopathy: findings from the International T1 Multicenter Cardiovascular Magnetic Resonance Study. Circ Cardiovasc Imaging. 2015;8(12):e003285. https://doi.org/10.1161/CIRCIMAGING. 115.003285 .

93. Maron BJ. Contemporary insights and strategies for risk stratification and prevention of sudden death in hypertrophic cardiomyopathy. Circulation. 2010;121(3):445-56. https://doi.org/10.1161/ CIRCULATIONAHA.109.878579.

94. Grajewski KG, Stojanovska J, Ibrahim EH, Sayyouh M, Attili A. Left ventricular hypertrophy: evaluation with cardiac MRI. Curr Probl Diagn Radiol. 2019;49(6):460-75. https://doi.org/10.1067/j. cpradiol.2019.09.005.

95. Adabag AS, Maron BJ, Appelbaum E, Harrigan CJ, Buros JL, Gibson CM, et al. Occurrence and frequency of arrhythmias in hypertrophic cardiomyopathy in relation to delayed enhancement on cardiovascular magnetic resonance. J Am Coll Cardiol. 2008;51(14):1369-74. https://doi.org/10.1016/j.jacc.2007.11. 071.

96.• Weng Z, Yao J, Chan RH, He J, Yang X, Zhou Y, et al. Prognostic value of LGE-CMR in HCM: a meta-analysis. JACC Cardiovasc Imaging. 2016;9(12):1392-402. https://doi.org/10.1016/j.jcmg. 2016.02.031 This meta-analysis demonstrated the prognostic value of LGE in SCD prediction in patients with HCM.

97. Xu J, Zhuang B, Sirajuddin A, Li S, Huang J, Yin G, et al. MRI T1 mapping in hypertrophic cardiomyopathy: evaluation in patients without late gadolinium enhancement and hemodynamic obstruction. Radiology. 2020;294(2):275-86. https://doi.org/10.1148/ radiol.2019190651.

98. Seferovic PM, Polovina M, Bauersachs J, Arad M, Gal TB, Lund LH, et al. Heart failure in cardiomyopathies: a position paper from the Heart Failure Association of the European Society of Cardiology. Eur J Heart Fail. 2019;21(5):553-76. https://doi.org/ 10.1002/ejhf.1461.

99. Raman B, Ariga R, Spartera M, Sivalokanathan S, Chan K, Dass $\mathrm{S}$, et al. Progression of myocardial fibrosis in hypertrophic cardiomyopathy: mechanisms and clinical implications. Eur Heart J Cardiovasc Imaging. 2019;20(2):157-67. https://doi.org/10. 1093/ehjci/jey135.

100. Todiere G, Aquaro GD, Piaggi P, Formisano F, Barison A, Masci $\mathrm{PG}$, et al. Progression of myocardial fibrosis assessed with cardiac magnetic resonance in hypertrophic cardiomyopathy. J Am Coll Cardiol. 2012;60(10):922-9. https://doi.org/10.1016/j.jacc.2012. 03.076 .

101. Dalal D, Nasir K, Bomma C, Prakasa K, Tandri H, Piccini J, et al. Arrhythmogenic right ventricular dysplasia: a United States experience. Circulation. 2005;112(25):3823-32. https://doi.org/10. 1161/CIRCULATIONAHA.105.542266.

102. te Riele AS, Tandri H, Bluemke DA. Arrhythmogenic right ventricular cardiomyopathy (ARVC): cardiovascular magnetic resonance update. J Cardiovasc Magn Reson. 2014;16(1):50. https:// doi.org/10.1186/s12968-014-0050-8.

103. Marcus FI, Fontaine GH, Guiraudon G, Frank R, Laurenceau JL, Malergue C, et al. Right ventricular dysplasia: a report of 24 adult cases. Circulation. 1982;65(2):384-98. https://doi.org/10.1161/ 01.cir.65.2.384.

104. Marcus FI, McKenna WJ, Sherrill D, Basso C, Bauce B, Bluemke DA, et al. Diagnosis of arrhythmogenic right ventricular cardiomyopathy/dysplasia: proposed modification of the task force criteria. Circulation. 2010;121(13):1533-41. https://doi.org/10. 1161/CIRCULATIONAHA.108.840827.

105. Galea N, Carbone I, Cannata D, Cannavale G, Conti B, Galea R, et al. Right ventricular cardiovascular magnetic resonance imaging: normal anatomy and spectrum of pathological findings. Insights Imaging. 2013;4(2):213-23. https://doi.org/10.1007/ s13244-013-0222-3.

106. Sen-Chowdhry S, Syrris P, Ward D, Asimaki A, Sevdalis E, McKenna WJ. Clinical and genetic characterization of families with arrhythmogenic right ventricular dysplasia/cardiomyopathy 
provides novel insights into patterns of disease expression. Circulation. 2007;115(13):1710-20. https://doi.org/10.1161/ CIRCULATIONAHA.106.660241.

107. Basso C, Bauce B, Corrado D, Thiene G. Pathophysiology of arrhythmogenic cardiomyopathy. Nat Rev Cardiol. 2011;9(4): 223-33. https://doi.org/10.1038/nrcardio.2011.173.

108. Hunold P, Wieneke H, Bruder O, Krueger U, Schlosser T, Erbel $\mathrm{R}$, et al. Late enhancement: a new feature in MRI of arrhythmogenic right ventricular cardiomyopathy? J Cardiovasc Magn Reson. 2005;7(4):649-55. https://doi.org/10.1081/jcmr200065608 .

109. Tandri H, Saranathan M, Rodriguez ER, Martinez C, Bomma C, Nasir K, et al. Noninvasive detection of myocardial fibrosis in arrhythmogenic right ventricular cardiomyopathy using delayedenhancement magnetic resonance imaging. J Am Coll Cardiol. 2005;45(1):98-103. https://doi.org/10.1016/j.jacc.2004.09.053.

110. Pfluger HB, Phrommintikul A, Mariani JA, Cherayath JG, Taylor AJ. Utility of myocardial fibrosis and fatty infiltration detected by cardiac magnetic resonance imaging in the diagnosis of arrhythmogenic right ventricular dysplasia-a single centre experience. Heart Lung Circ. 2008;17(6):478-83. https://doi.org/10.1016/j. hlc.2008.03.085.

111. Zghaib T, Ghasabeh MA, Assis FR, Chrispin J, Keramati A, Misra $\mathrm{S}$, et al. Regional strain by cardiac magnetic resonance imaging improves detection of right ventricular scar compared with late gadolinium enhancement on a multimodality scar evaluation in patients with arrhythmogenic right ventricular cardiomyopathy. Circ Cardiovasc Imaging. 2018;11(9):e007546. https://doi.org/ 10.1161/CIRCIMAGING.118.007546.

112. Corrado D, Link MS, Calkins H. Arrhythmogenic right ventricular cardiomyopathy. N Engl J Med. 2017;376(1):61-72. https://doi. org/10.1056/NEJMra1509267.

113. Aquaro GD, Pingitore A, Di Bella G, Piaggi P, Gaeta R, Grigoratos $\mathrm{C}$, et al. Prognostic role of cardiac magnetic resonance in arrhythmogenic right ventricular cardiomyopathy. Am J Cardiol. 2018;122(10):1745-53. https://doi.org/10.1016/j. amjcard.2018.08.007.

114. Shen MT, Yang ZG, Diao KY, Jiang L, Zhang Y, Liu X, et al. Left ventricular involvement in arrhythmogenic right ventricular dysplasia/cardiomyopathy predicts adverse clinical outcomes: a cardiovascular magnetic resonance feature tracking study. Sci Rep. 2019;9(1):14235. https://doi.org/10.1038/s41598-01950535-z.

115. Fontana M, Corovic A, Scully P, Moon JC. Myocardial amyloidosis: the exemplar interstitial disease. JACC Cardiovasc Imaging. 2019;12(11 Pt 2):2345-56. https://doi.org/10.1016/j.jcmg.2019. 06.023.

116. Manolis AS, Manolis AA, Manolis TA, Melita H. Cardiac amyloidosis: an underdiagnosed/underappreciated disease. Eur J Intern Med. 2019;67:1-13. https://doi.org/10.1016/j.ejim.2019. 07.022 .

117. Fontana M, Pica S, Reant P, Abdel-Gadir A, Treibel TA, Banypersad SM, et al. Prognostic value of late gadolinium enhancement cardiovascular magnetic resonance in cardiac amyloidosis. Circulation. 2015;132(16):1570-9. https://doi.org/10. 1161/CIRCULATIONAHA.115.016567.

118. Baggiano A, Boldrini M, Martinez-Naharro A, Kotecha T, Petrie A, Rezk T, et al. Noncontrast magnetic resonance for the diagnosis of cardiac amyloidosis. JACC Cardiovasc Imaging. 2020;13(1 Pt 1):69-80. https://doi.org/10.1016/j.jcmg.2019.03.026 This study assessed the diagnostic value of native $\mathrm{T} 1$ in patients with suspected systemic amyloidosis.

119. Syed IS, Glockner JF, Feng D, Araoz PA, Martinez MW, Edwards $\mathrm{WD}$, et al. Role of cardiac magnetic resonance imaging in the detection of cardiac amyloidosis. JACC Cardiovasc Imaging. 2010;3(2):155-64. https://doi.org/10.1016/j.jcmg.2009.09.023.
120. Martinez-Naharro A, Kotecha T, Norrington K, Boldrini M, Rezk $\mathrm{T}$, Quarta C, et al. Native T1 and extracellular volume in transthyretin amyloidosis. JACC Cardiovasc Imaging. 2019;12(5):810-9. https://doi.org/10.1016/j.jcmg.2018.02.006.

121. Brownrigg J, Lorenzini M, Lumley M, Elliott P. Diagnostic performance of imaging investigations in detecting and differentiating cardiac amyloidosis: a systematic review and meta-analysis. ESC Heart Fail. 2019;6(5):1041-51. https://doi.org/10.1002/ehf2. 12511.

122. Chacko L, Martone R, Cappelli F, Fontana M. Cardiac amyloidosis: updates in imaging. Curr Cardiol Rep. 2019;21(9):108. https://doi.org/10.1007/s11886-019-1180-2.

123. Martinez-Naharro A, Treibel TA, Abdel-Gadir A, Bulluck H, Zumbo G, Knight DS, et al. Magnetic resonance in transthyretin cardiac amyloidosis. J Am Coll Cardiol. 2017;70(4):466-77. https://doi.org/10.1016/j.jacc.2017.05.053.

124. Banypersad SM, Fontana M, Maestrini V, Sado DM, Captur G, Petrie A, et al. T1 mapping and survival in systemic light-chain amyloidosis. Eur Heart J. 2015;36(4):244-51. https://doi.org/10. 1093/eurheartj/ehu444.

125. Williams LK, Forero JF, Popovic ZB, Phelan D, Delgado D, Rakowski $\mathrm{H}$, et al. Patterns of CMR measured longitudinal strain and its association with late gadolinium enhancement in patients with cardiac amyloidosis and its mimics. J Cardiovasc Magn Reson. 2017;19(1):61. https://doi.org/10.1186/s12968-017-03760 .

126. Dungu JN, Valencia O, Pinney JH, Gibbs SD, Rowczenio D, Gilbertson JA, et al. CMR-based differentiation of AL and ATTR cardiac amyloidosis. JACC Cardiovasc Imaging. 2014;7(2):133-42. https://doi.org/10.1016/j.jcmg.2013.08.015.

127. Ridouani F, Damy T, Tacher V, Derbel H, Legou F, Sifaoui I, et al. Myocardial native T2 measurement to differentiate lightchain and transthyretin cardiac amyloidosis and assess prognosis. J Cardiovasc Magn Reson. 2018;20(1):58. https://doi.org/10. 1186/s12968-018-0478-3.

128. Wan K, Sun J, Han Y, Luo Y, Liu H, Yang D, et al. Right ventricular involvement evaluated by cardiac magnetic resonance imaging predicts mortality in patients with light chain amyloidosis. Heart Vessel. 2018;33(2):170-9. https://doi.org/10.1007/s00380017-1043-y.

129. Illman JE, Arunachalam SP, Arani A, Chang IC, Glockner JF, Dispenzieri A, et al. MRI feature tracking strain is prognostic for all-cause mortality in AL amyloidosis. Amyloid. 2018;25(2):1018. https://doi.org/10.1080/13506129.2018.1465406.

130. Martinez-Naharro A, Abdel-Gadir A, Treibel TA, Zumbo G, Knight DS, Rosmini S, et al. CMR-verified regression of cardiac AL amyloid after chemotherapy. JACC Cardiovasc Imaging. 2018;11(1):152-4. https://doi.org/10.1016/j.jcmg.2017.02.012.

131. Pollack A, Kontorovich AR, Fuster V, Dec GW. Viral myocarditis-diagnosis, treatment options, and current controversies. Nat Rev Cardiol. 2015;12(11):670-80. https://doi.org/10.1038/ nrcardio.2015.108.

132. Friedrich MG, Sechtem U, Schulz-Menger J, Holmvang G, Alakija P, Cooper LT, et al. Cardiovascular magnetic resonance in myocarditis: a JACC White Paper. J Am Coll Cardiol. 2009;53(17):1475-87. https://doi.org/10.1016/j.jacc.2009.02. 007.

133. Lurz P, Eitel I, Adam J, Steiner J, Grothoff M, Desch S, et al Diagnostic performance of CMR imaging compared with EMB in patients with suspected myocarditis. JACC Cardiovasc Imaging. 2012;5(5):513-24. https://doi.org/10.1016/j.jcmg.2011. 11.022.

134. Pan JA, Lee YJ, Salerno M. Diagnostic performance of extracellular volume, native T1, and T2 mapping versus Lake Louise criteria by cardiac magnetic resonance for detection of acute 
myocarditis: a meta-analysis. Circ Cardiovasc Imaging. 2018;11(7):e007598. https://doi.org/10.1161/CIRCIMAGING. 118.007598 .

135. Lurz P, Luecke C, Eitel I, Fohrenbach F, Frank C, Grothoff M, et al. Comprehensive cardiac magnetic resonance imaging in patients with suspected myocarditis: the MyoRacer-Trial. J Am Coll Cardiol. 2016;67(15):1800-11. https://doi.org/10.1016/j.jacc. 2016.02.013.

136. von Knobelsdorff-Brenkenhoff F, Schuler J, Doganguzel S, Dieringer MA, Rudolph A, Greiser A, et al. Detection and monitoring of acute myocarditis applying quantitative cardiovascular magnetic resonance. Circ Cardiovasc Imaging. 2017;10(2): e005242. https://doi.org/10.1161/CIRCIMAGING.116.005242.

137.• Ferreira VM, Schulz-Menger J, Holmvang G, Kramer CM, Carbone I, Sechtem U, et al. Cardiovascular magnetic resonance in nonischemic myocardial inflammation: expert recommendations. J Am Coll Cardiol. 2018;72(24):3158-76. https://doi.org/ 10.1016/j.jacc.2018.09.072 This review updated the criteria for diagnosing myocarditis based on CMR findings.

138. Caforio AL, Pankuweit S, Arbustini E, Basso C, Gimeno-Blanes J, Felix SB, et al. Current state of knowledge on aetiology, diagnosis, management, and therapy of myocarditis: a position statement of the European Society of Cardiology Working Group on Myocardial and Pericardial Diseases. Eur Heart J. 2013;34(33): 2636-48, 2648a-2648d. https://doi.org/10.1093/eurheartj/eht210.

139. Bozkurt B, Colvin M, Cook J, Cooper LT, Deswal A, Fonarow $\mathrm{GC}$, et al. Current diagnostic and treatment strategies for specific dilated cardiomyopathies: a scientific statement from the American Heart Association. Circulation. 2016;134(23):e579 646. https://doi.org/10.1161/CIR.0000000000000455.

140. Shi S, Qin M, Shen B, Cai Y, Liu T, Yang F, et al. Association of cardiac injury with mortality in hospitalized patients with COVID19 in Wuhan, China. JAMA Cardiol. 2020;5(7):802-10. https:// doi.org/10.1001/jamacardio.2020.0950.

141. Huang L, Zhao P, Tang D, Zhu T, Han R, Zhan C, et al. Cardiac involvement in patients recovered from COVID-2019 identified using magnetic resonance imaging. JACC Cardiovasc Imaging. 2020;13(11):2330-9. https://doi.org/10.1016/j.jcmg.2020.05.004.

142. Puntmann VO, Carerj ML, Wieters I, Fahim M, Arendt C, Hoffmann J, et al. Outcomes of cardiovascular magnetic resonance imaging in patients recently recovered from coronavirus disease 2019 (COVID-19). JAMA Cardiol. 2020;5(11):126573. https://doi.org/10.1001/jamacardio.2020.3557.

143. Clark DE, Parikh A, Dendy JM, Diamond AB, George-Durrett K, Fish FA, et al. medRxiv. 2020. https://doi.org/10.1101/2020.08. 31.20185140

144. Grun S, Schumm J, Greulich S, Wagner A, Schneider S, Bruder O, et al. Long-term follow-up of biopsy-proven viral myocarditis: predictors of mortality and incomplete recovery. J Am Coll Cardiol. 2012;59(18):1604-15. https://doi.org/10.1016/j.jacc. 2012.01.007.

145. Grani C, Eichhorn C, Biere L, Murthy VL, Agarwal V, Kaneko K, et al. Prognostic value of cardiac magnetic resonance tissue characterization in risk stratifying patients with suspected myocarditis. J Am Coll Cardiol. 2017;70(16):1964-76. https://doi.org/10. 1016/j.jacc.2017.08.050.

146. Schumm J, Greulich S, Wagner A, Grun S, Ong P, Bentz K, et al. Cardiovascular magnetic resonance risk stratification in patients with clinically suspected myocarditis. J Cardiovasc Magn Reson. 2014;16(1):14. https://doi.org/10.1186/1532-429X-16-14.

147. Kusano KF, Satomi K. Diagnosis and treatment of cardiac sarcoidosis. Heart. 2016;102(3):184-90. https://doi.org/10.1136/heartjnl2015-307877.

148. Muchtar E, Blauwet LA, Gertz MA. Restrictive cardiomyopathy: genetics, pathogenesis, clinical manifestations, diagnosis, and therapy. Circ Res. 2017;121(7):819-37. https://doi.org/10.1161/ CIRCRESAHA.117.310982.

149. Gideon NM, Mannino DM. Sarcoidosis mortality in the United States 1979-1991: an analysis of multiple-cause mortality data. Am J Med. 1996;100(4):423-7. https://doi.org/10.1016/S00029343(97)89518-6.

150. Terasaki F, Yoshinaga K. New guidelines for diagnosis of cardiac sarcoidosis in Japan. Ann Nucl Cardiol. 2017;3(1):42-5. https:// doi.org/10.17996/anc.17-00042.

151. Birnie DH, Sauer WH, Bogun F, Cooper JM, Culver DA, Duvernoy CS, et al. HRS expert consensus statement on the diagnosis and management of arrhythmias associated with cardiac sarcoidosis. Heart Rhythm. 2014;11(7):1305-23. https://doi.org/ 10.1016/j.hrthm.2014.03.043.

152. Smedema JP, Snoep G, van Kroonenburgh MP, van Geuns RJ, Dassen WR, Gorgels AP, et al. Evaluation of the accuracy of gadolinium-enhanced cardiovascular magnetic resonance in the diagnosis of cardiac sarcoidosis. J Am Coll Cardiol. 2005;45(10):1683-90. https://doi.org/10.1016/j.jacc.2005.01. 047.

153. Patel MR, Cawley PJ, Heitner JF, Klem I, Parker MA, Jaroudi WA, et al. Detection of myocardial damage in patients with sarcoidosis. Circulation. 2009;120(20):1969-77. https://doi.org/10. 1161/CIRCULATIONAHA.109.851352.

154. Watanabe E, Kimura F, Nakajima T, Hiroe M, Kasai Y, Nagata $\mathrm{M}$, et al. Late gadolinium enhancement in cardiac sarcoidosis: characteristic magnetic resonance findings and relationship with left ventricular function. J Thorac Imaging. 2013;28(1):60-6. https://doi.org/10.1097/RTI.0b013e3182761830.

155. Kouranos V, Tzelepis GE, Rapti A, Mavrogeni S, Aggeli K, Douskou M, et al. Complementary role of CMR to conventional screening in the diagnosis and prognosis of cardiac sarcoidosis. JACC Cardiovasc Imaging. 2017;10(12):1437-47. https://doi. org/10.1016/j.jcmg.2016.11.019.

156. Okasha O, Kazmirczak F, Chen KA, Farzaneh-Far A, Shenoy C. Myocardial involvement in patients with histologically diagnosed cardiac sarcoidosis: a systematic review and meta-analysis of gross pathological images from autopsy or cardiac transplantation cases. J Am Heart Assoc. 2019;8(10):e011253. https://doi.org/10. 1161/JAHA.118.011253.

157. Greulich S, Deluigi CC, Gloekler S, Wahl A, Zurn C, Kramer U, et al. CMR imaging predicts death and other adverse events in suspected cardiac sarcoidosis. JACC Cardiovasc Imaging. 2013;6(4):501-11. https://doi.org/10.1016/j.jcmg.2012.10.021.

158. Smedema JP, van Geuns RJ, Ector J, Heidbuchel H, Ainslie G, Crijns H. Right ventricular involvement and the extent of left ventricular enhancement with magnetic resonance predict adverse outcome in pulmonary sarcoidosis. ESC Heart Fail. 2018;5(1): 157-71. https://doi.org/10.1002/ehf2.12201.

159. Kagioka Y, Yasuda M, Okune M, Kakehi K, Kawamura T, Kobuke K, et al. Right ventricular involvement is an important prognostic factor and risk stratification tool in suspected cardiac sarcoidosis: analysis by cardiac magnetic resonance imaging. Clin Res Cardiol. 2019;109(8):988-98. https://doi.org/10.1007/ s00392-019-01591-y.

160. Khush KK, Cherikh WS, Chambers DC, Harhay MO, Hayes D Jr, Hsich E, et al. The International Thoracic Organ Transplant Registry of the International Society for Heart and Lung Transplantation: thirty-sixth adult heart transplantation report 2019; focus theme: donor and recipient size match. J Heart Lung Transplant. 2019;38(10):1056-66. https://doi.org/10.1016/j. healun.2019.08.004.

161. Marie PY, Angioi M, Carteaux JP, Escanye JM, Mattei S, Tzvetanov K, et al. Detection and prediction of acute heart transplant rejection with the myocardial $\mathrm{T} 2$ determination provided by a black-blood magnetic resonance imaging sequence. J Am Coll 
Cardiol. 2001;37(3):825-31. https://doi.org/10.1016/s07351097(00)01196-7.

162. Usman AA, Taimen K, Wasielewski M, McDonald J, Shah S, Giri $\mathrm{S}$, et al. Cardiac magnetic resonance T2 mapping in the monitoring and follow-up of acute cardiac transplant rejection: a pilot study. Circ Cardiovasc Imaging. 2012;5(6):782-90. https://doi.org/10. 1161/CIRCIMAGING.111.971101.

163. Bonnemains L, Villemin T, Escanye JM, Hossu G, Odille F, Vanhuyse F, et al. Diagnostic and prognostic value of MRI T2 quantification in heart transplant patients. Transpl Int. 2014;27(1): 69-76. https://doi.org/10.1111/tri.12222.

164. Imran M, Wang L, McCrohon J, Yu C, Holloway C, Otton J, et al. Native T1 mapping in the diagnosis of cardiac allograft rejection: a prospective histologically validated study. JACC Cardiovasc Imaging. 2019;12(8 Pt 2):1618-28. https://doi.org/10.1016/j. jemg.2018.10.027.

165. Dolan RS, Rahsepar AA, Blaisdell J, Suwa K, Ghafourian K, Wilcox JE, et al. Multiparametric cardiac magnetic resonance imaging can detect acute cardiac allograft rejection after heart transplantation. JACC Cardiovasc Imaging. 2019;12(8 Pt 2):1632-41. https://doi.org/10.1016/j.jcmg.2019.01.026.

166. Miller CA, Sarma J, Naish JH, Yonan N, Williams SG, Shaw SM, et al. Multiparametric cardiovascular magnetic resonance assessment of cardiac allograft vasculopathy. J Am Coll Cardiol. 2014;63(8):799-808. https://doi.org/10.1016/j.jacc.2013.07.119.

167. Myerson SG. Heart valve disease: investigation by cardiovascular magnetic resonance. J Cardiovasc Magn Reson. 2012;14(1):7. https://doi.org/10.1186/1532-429X-14-7.

168. Bing R, Cavalcante JL, Everett RJ, Clavel MA, Newby DE, Dweck MR. Imaging and impact of myocardial fibrosis in aortic stenosis. JACC Cardiovasc Imaging. 2019;12(2):283-96. https:// doi.org/10.1016/j.jcmg.2018.11.026.

169. Chen H, Zeng J, Liu D, Yang Q. Prognostic value of late gadolinium enhancement on CMR in patients with severe aortic valve disease: a systematic review and meta-analysis. Clin Radiol. 2018;73(11):983.e7-983.e. https://doi.org/10.1016/j.crad.2018. 07.095 .

170. Balciunaite G, Skorniakov V, Rimkus A, Zaremba T, Palionis D, Valeviciene N, et al. Prevalence and prognostic value of late gadolinium enhancement on CMR in aortic stenosis: meta-analysis. Eur Radiol. 2020;30(1):640-51. https://doi.org/10.1007/s00330019-06386-3

171. Everett RJ, Treibel TA, Fukui M, Lee H, Rigolli M, Singh A, et al. Extracellular myocardial volume in patients with aortic stenosis. J Am Coll Cardiol. 2020;75(3):304-16. https://doi.org/10.1016/j. jacc.2019.11.032.

172. Ruile P, Blanke P, Krauss T, Dorfs S, Jung B, Jander N, et al. Preprocedural assessment of aortic annulus dimensions for transcatheter aortic valve replacement: comparison of a non-contrast 3D MRA protocol with contrast-enhanced cardiac dual-source CT angiography. Eur Heart J Cardiovasc Imaging. 2016;17(4):45866. https://doi.org/10.1093/ehjci/jev188.

173. Wang J, Jagasia DH, Kondapally YR, Herrmann HC, Han Y. Comparison of non-contrast cardiovascular magnetic resonance imaging to computed tomography angiography for aortic annular sizing before transcatheter aortic valve replacement. J Invasive Cardiol. 2017;29(7):239-45.

174. Hayashida K, Lefevre T, Chevalier B, Hovasse T, Romano M, Garot $\mathrm{P}$, et al. Impact of post-procedural aortic regurgitation on mortality after transcatheter aortic valve implantation. JACC Cardiovasc Interv. 2012;5(12):1247-56. https://doi.org/10.1016/ j.jcin.2012.09.003.

175. Ribeiro HB, Orwat S, Hayek SS, Larose E, Babaliaros V, Dahou A, et al. Cardiovascular magnetic resonance to evaluate aortic regurgitation after transcatheter aortic valve replacement. J Am
Coll Cardiol. 2016;68(6):577-85. https://doi.org/10.1016/j.jacc. 2016.05.059.

176. Garg P, Swift AJ, Zhong L, Carlhall CJ, Ebbers T, Westenberg J, et al. Assessment of mitral valve regurgitation by cardiovascular magnetic resonance imaging. Nat Rev Cardiol. 2019;17(5):298 312. https://doi.org/10.1038/s41569-019-0305-z.

177. Han Y, Peters DC, Salton CJ, Bzymek D, Nezafat R, Goddu B, et al. Cardiovascular magnetic resonance characterization of mitral valve prolapse. JACC Cardiovasc Imaging. 2008;1(3):294-303. https://doi.org/10.1016/j.jcmg.2008.01.013.

178. Van De Heyning CM, Magne J, Pierard LA, Bruyere PJ, Davin L, De Maeyer C, et al. Late gadolinium enhancement CMR in primary mitral regurgitation. Eur J Clin Investig. 2014;44(9):840-7. https://doi.org/10.1111/eci.12306.

179. Edwards NC, Moody WE, Yuan M, Weale P, Neal D, Townend $J \mathrm{~N}$, et al. Quantification of left ventricular interstitial fibrosis in asymptomatic chronic primary degenerative mitral regurgitation. Circ Cardiovasc Imaging. 2014;7(6):946-53. https://doi.org/10. 1161/CIRCIMAGING.114.002397.

180. Myerson SG, d'Arcy J, Christiansen JP, Dobson LE, Mohiaddin R, Francis JM, et al. Determination of clinical outcome in mitral regurgitation with cardiovascular magnetic resonance quantification. Circulation. 2016;133(23):2287-96. https://doi.org/10.1161/ CIRCULATIONAHA.115.017888.

181. Penicka M, Vecera J, Mirica DC, Kotrc M, Kockova R, Van Camp G. Prognostic implications of magnetic resonance-derived quantification in asymptomatic patients with organic mitral regurgitation: comparison with Doppler echocardiography-derived integrative approach. Circulation. 2018;137(13):1349-60. https:// doi.org/10.1161/CIRCULATIONAHA.117.029332.

182. Kojima S, Yamada N, Goto Y. Diagnosis of constrictive pericarditis by tagged cine magnetic resonance imaging. $\mathrm{N}$ Engl J Med. $1999 ; 341$ (5):373-4. https://doi.org/10.1056/ NEJM199907293410515.

183. Power JA, Thompson DV, Rayarao G, Doyle M, Biederman RW. Cardiac magnetic resonance radiofrequency tissue tagging for diagnosis of constrictive pericarditis: a proof of concept study. J Thorac Cardiovasc Surg. 2016;151(5):1348-55. https://doi.org/ 10.1016/j.jtcvs.2015.12.035.

184. Taylor AM, Dymarkowski S, Verbeken EK, Bogaert J. Detection of pericardial inflammation with late-enhancement cardiac magnetic resonance imaging: initial results. Eur Radiol. 2006;16(3): 569-74. https://doi.org/10.1007/s00330-005-0025-0.

185. Imazio M, Pivetta E, Palacio Restrepo S, Sormani P, Pedrotti P, Quarta G, et al. Usefulness of cardiac magnetic resonance for recurrent pericarditis. Am J Cardiol. 2020;125(1):146-51. https://doi.org/10.1016/j.amjcard.2019.09.026.

186. Konstam MA, Kiernan MS, Bernstein D, Bozkurt B, Jacob M, Kapur NK, et al. Evaluation and management of right-sided heart failure: a scientific statement from the American Heart Association. Circulation. 2018;137(20):e578-622. https://doi. org/10.1161/CIR.0000000000000560.

187. Baggen VJ, Leiner T, Post MC, van Dijk AP, Roos-Hesselink JW, Boersma E, et al. Cardiac magnetic resonance findings predicting mortality in patients with pulmonary arterial hypertension: a systematic review and meta-analysis. Eur Radiol. 2016;26(11):377180. https://doi.org/10.1007/s00330-016-4217-6.

188. Altmayer SPL, Han QJ, Addetia K, Patel AR, Forfia PR, Han Y. Using all-cause mortality to define severe RV dilation with RV/ LV volume ratio. Sci Rep. 2018;8(1):7200. https://doi.org/10. 1038/s41598-018-25259-1.

189. Blyth KG, Groenning BA, Martin TN, Foster JE, Mark PB, Dargie $\mathrm{HJ}$, et al. Contrast enhanced-cardiovascular magnetic resonance imaging in patients with pulmonary hypertension. Eur Heart J. 2005;26(19):1993-9. https://doi.org/10.1093/eurheartj/ehi328. 
190. Shehata ML, Lossnitzer D, Skrok J, Boyce D, Lechtzin N, Mathai $\mathrm{SC}$, et al. Myocardial delayed enhancement in pulmonary hypertension: pulmonary hemodynamics, right ventricular function, and remodeling. AJR Am J Roentgenol. 2011;196(1):87-94. https:// doi.org/10.2214/AJR.09.4114.

191. Freed BH, Gomberg-Maitland M, Chandra S, Mor-Avi V, Rich S, Archer SL, et al. Late gadolinium enhancement cardiovascular magnetic resonance predicts clinical worsening in patients with pulmonary hypertension. J Cardiovasc Magn Reson. 2012;14(1): 11. https://doi.org/10.1186/1532-429X-14-11.

192. Marrouche NF, Brachmann J, Andresen D, Siebels J, Boersma L, Jordaens L, et al. Catheter ablation for atrial fibrillation with heart failure. N Engl J Med. 2018;378(5):417-27. https://doi.org/10. 1056/NEJMoa1707855.

193. Turagam MK, Garg J, Whang W, Sartori S, Koruth JS, Miller MA, et al. Catheter ablation of atrial fibrillation in patients with heart failure: a meta-analysis of randomized controlled trials. Ann Intern Med. 2019;170(1):41-50. https://doi.org/10.7326/M180992.

194. Marrouche NF, Wilber D, Hindricks G, Jais P, Akoum N, Marchlinski F, et al. Association of atrial tissue fibrosis identified by delayed enhancement MRI and atrial fibrillation catheter ablation: the DECAAF study. JAMA. 2014;311(5):498-506. https:// doi.org/10.1001/jama.2014.3.

195. Begg GA, Swoboda PP, Karim R, Oesterlein T, Rhode K, Holden $\mathrm{AV}$, et al. Imaging, biomarker and invasive assessment of diffuse left ventricular myocardial fibrosis in atrial fibrillation. $\mathrm{J}$ Cardiovasc Magn Reson. 2020;22(1):13. https://doi.org/10.1186/ s12968-020-0603-y.
196. Neilan TG, Mongeon FP, Shah RV, Coelho-Filho O, Abbasi SA, Dodson JA, et al. Myocardial extracellular volume expansion and the risk of recurrent atrial fibrillation after pulmonary vein isolation. JACC Cardiovasc Imaging. 2014;7(1):1-11. https://doi.org/ 10.1016/j.jcmg.2013.08.013.

197. Bisbal F, Guiu E, Cabanas-Grandio P, Berruezo A, Prat-Gonzalez $\mathrm{S}$, Vidal B, et al. CMR-guided approach to localize and ablate gaps in repeat AF ablation procedure. JACC Cardiovasc Imaging. 2014;7(7):653-63. https://doi.org/10.1016/j.jcmg.2014.01.014.

198. Andreu D, Ortiz-Perez JT, Boussy T, Fernandez-Armenta J, de Caralt TM, Perea RJ, et al. Usefulness of contrast-enhanced cardiac magnetic resonance in identifying the ventricular arrhythmia substrate and the approach needed for ablation. Eur Heart J. 2014;35(20):1316-26. https://doi.org/10.1093/eurheartj/eht510.

199. Piers SR, Tao Q, de Riva SM, Siebelink HM, Schalij MJ, van der Geest RJ, et al. CMR-based identification of critical isthmus sites of ischemic and nonischemic ventricular tachycardia. JACC Cardiovasc Imaging. 2014;7(8):774-84. https://doi.org/10.1016/ j.jcmg.2014.03.013.

200. Dukkipati SR, Sanz J. Contrast-enhanced CMR imaging of ventricular tachycardia isthmus sites to guide ablation: an approach in evolution. JACC Cardiovasc Imaging. 2014;7(8):785-7. https:// doi.org/10.1016/j.jcmg.2014.06.008.

201. O’Neill M, Razavi R, Harrison JL, Whitaker J, Williams SE, Chubb H. Cardiac electrophysiology under MRI guidance: an emerging technology. Arrhythmia Electrophysiol Rev. 2017;6(2):85-93. https://doi.org/10.15420/aer.2017.1.2.

Publisher's Note Springer Nature remains neutral with regard to jurisdictional claims in published maps and institutional affiliations. 